\title{
¿Qué es ser «persona» para el Derecho?
}

\section{Carlos Fernández Sessarego}

\section{La persona como tema central del derecho}

La persona es, sin duda, el tema central del derecho. Lo recordó en el Perú, en 1962 y en ajustados términos, el maestro José León Barandiarán al expresar que «la calificación del ente humano sub specie juris es tema fundamental de la ciencia jurídica. Es su tema central. Por eso continuamente es necesario recapacitar en él, e ir considerando y reconsiderando los complejos asuntos que se ofrecen dentro de la unidad del tema»" . En la Argentina lo había anticipado el maestro cordobés Alfredo Orgaz quien, en 1946, al referirse a la persona, manifestó que «se tiene que fijar con claridad y precisión un concepto que juega papel tan decisivo en nuestra sistemática jurídica ${ }^{2}$, mientras que, un año después, en 1947, Ramón $M$. Alsina señalaba que «todo detenido examen de la sociedad, el derecho y el Estado, debe necesariamente girar en torno a la persona humana, principio, medio y fin de ellos, a punto tal que fija su sentido y destino, como la evolución humana lo pone de manifiesto» ${ }^{3}$.

1 José Lcón Barandiarán, en el Prólogo a la primera edición del libro del autor de este trabajo La noción juridica de persona, publicado por la Universidad Nacional Mayor de San Marcos de Lima en el año de 1962, p. 11. Existe una segunda edición, editada por la misma Universidad, correspondiente al año 1968.

2 Alfredo Orgaz, Personas individuales, Editorial Depalma, Buenos Aires, 1946, p. 3.

3 Ramón M. Alsina, en el prólogo a la obra Persona y Derecho de David Zambrano (h), Valerio Abeledo, Buenos Aires, 1947, p. 1. 
En España, el tratadista José Castán Tobeñas, en 1952, sostiene escuetamente «que el hombre es el centro del Derecho» ${ }^{4}$, mientras que el jusfilósofo Ulrich Klug confirma este aserto cuando dice que, "fundamentalmente, el hombre es ciertamente el centro del derecho, y esto especialmente en la sensibilidad jurídica moderna " 5 . Ennecerus, en Alemania, considera que «la persona constituye la condición previa de todos los derechos" ${ }^{6}$. Savatier, en Francia, expresa, por su parte, que la persona se ha convertido uen el centro de la meditación jurídica contemporánea ${ }^{7}$.

Lo expuesto nos revela que, desde las décadas anteriores a la primera mitad del siglo XX, el concepto de persona era considerado por los juristas y jusfilósofos, casi unánimemente, no sólo como el tema central del derecho sino que, al mismo tiempo, resultaba ser una noción problemática. Cabe señalar que designamos como "problema" algo que necesita de alguien que lo piense y para quien exista. Si bien es cierto que el problema, como anota Wagner de Reyna, está dado en la realidad siendo en cierto modo algo objetivo, -«posibilidades lógicas que están como el oro en las minas ${ }^{8}$ - no es menos evidente que para que algo se constituya en problema se requiere que con urgencia se necesite saber algo o compaginar verdades discordantes. El problema está ahí, como el oro en las minas, mientras no asumamos la difícil tarea de afrontarlo e intentar desentrañarlo.

La persona, contrariamente a lo que acontecía en siglos anteriores donde la protección de la propiedad era la principal preocupación del derecho, es actualmente considerada como el eje y el centro del derecho. Esta realidad se ha abierto paso penosamente en el tiempo dentro de la disciplina jurídica. Para que ello sucediera ha debido superarse tendencias y corrientes unidimensionales que hacían girar el derecho

4 José Castán Tobeñas, "Los derechos de la personalidad", en Revista General de Legislación y Jurisprudencia, 2a. Etapa, Tomo XXIV, Nº 192, Madrid, 1952, p. 5 y ss.

5 Ulrich Klug, "Tesis para un análisis de la idea del hombre dentro del Derecho", en Libro Homenaje a la memoria de Roberto Goldschmidt, Caracas, 1967, p. 80.

6 Ludwig Ennecerus, en Derecho Civil, Parte General, vol. I, Barcelona, 1934, p. 325.

7 René Savatier, Les metamorphoses economiques et sociales du droit privé d'aujorrd'hui, troisieme série, Librarie Dalloz, París, 1959, p. 5.

8 Alberto Wagner de Reyna, La filosofia en Jbero-América, Imprenta Santa María, Lima, 1949, p. 20. 
tan sólo en torno a los valores, como la justicia o, reductivamente, alrededor de la norma jurídica que es tan sólo, como se sabe, una estructura formal del pensar humano. La vida humana y los valores fueron considerados como lo metajurídico por un sector dominante de la doctrina jurídica bajo la inspiración de Hans Kelsen.

De otro lado, y con más fatiga, se ha debido también superar una concepción individualista-patrimonialista que se interesaba preferentemente por la protección jurídica de los intereses materiales de la persona - por su patrimonio- más que por la persona considerada en sí misma y, por consiguiente, por sus derechos subjetivos e intereses existenciales.

La posibilidad de superar ambos escollos que, como se ha expresado, se alzaban como obstáculos que impedían una precisa y clara aprehensión del significado de la persona para el derecho, se debe al decisivo aporte de la filosofía de la existencia, lo que ha permitido comprender cuál es la naturaleza misma del ser humano.

El humanismo o personalismo jurídico, cuya raíz histórica se encuentra en la doctrina cristiana, se desarrolla y profundiza por los pensadores que se adhieren, desde distintas vertientes ideológicas, a la filosofía de la existencia que surge en la primera mitad del siglo XX, en el periodo comprendido principalmente entre las dos guerras mundiales que asolaron la humanidad. Es a la sombra de esta corriente de pensamiento que se produce la revalorización de la persona humana ${ }^{9}$. El planteamiento filosófico, su significativo aporte, es recogido por el derecho.

Por dicha razón a la persona se le percibe en la actualidad como la creadora, destinataria y protagonista del derecho. La pregunta obligada, por ello, se centra en saber, en primera instancia, qué tipo de ente es éste que denominamos "persona” ${ }^{10}$ para, luego, preguntarnos por su significación jurídica.

9 Dentro de estos pensadores cabe citar, entre otros, a Jean Paul Sartre, Gabriel Marcel y Emmanuel Mounier, en Francia; Martín Heidegger y Karl Jaspers en Alemania; y Xavier Zubiri en España. Debe considerarse a Kierkegaard, que escribe en 1844 su obra El concepto de la angustia, como un válido predecesor de la filosofía de la existencia.

10 Se suele generalmente aludir al ente que somos con la expresión de "persona humana". En nuestro concepto resulta suficiente referirse a la "persona" pues no existe persona que, de suyo, no sca "humana". 


\section{Confusión acerca del significado de persona}

La noción jurídica de persona, en aquellas décadas vecinas a la primera mitad del siglo XX, no resultaba ni clara ni precisa, es decir, no reunía las dos condiciones que exigía Alfredo Orgaz para la cabal comprensión de la significación del concepto "persona", tal como se ha referido en precedencia. Contrariamente, la noción de persona se presentaba confusa, pues cada jurista o científico del derecho se hallaba obligado, necesariamente y como acto de fe, a tomar una determinada posición en torno a lo que se comprendía como persona para el derecho. Ello trajo consigo una impresionante multiplicación de enfoques a tal punto que incursionar en la materia era "como ingresar a una maraña impenetrable» ${ }^{11}$. No es, así, poca la confusión y la imprecisión que aparejaba, por aquel tiempo, el tema que venimos tratando.

La situación antes anotada lleva decir a Recaséns Siches que los juristas, al desentrañar la noción básica de persona, a menudo suelen involucrar cuestiones varias y heterogéneas que han generado una tal confusión "que ha embarullado de modo lamentable el pensamiento jurídico durante siglos" ${ }^{12}$. El propio jusfilósofo hispano comprueba y afirma que "los sociólogos y los juristas han producido una ingente y variada literatura en torno al concepto de persona»" ${ }^{13}$. Es, pues, confusión de siglos la que existe en torno a la persona.

\section{Probables causas de la confusión en torno a la noción de persona}

Frente a lo dicho en el parágrafo precedente, surge la insoslayable pregunta destinada a saber cuál o cuáles serían las causas o razones que motivan que en torno a la noción de persona exista la confusión advertida por no pocos juristas y jusfilósofos como, entre otros, por el citado de Recaséns Siches. A nuestro parecer, ellas son plurales. Trataremos, en las páginas siguientes, de esbozar algunas hipótesis en torno a este asun-

11 Carlos Fernández Sessarego, La noción juridica de persona, segunda edición, 1968, p. 18.

12 Luis Recaséns Siches, Tratado General de Filosofia del Derecho, Editorial Porrúa, segunda edición, México, 1961, p. 260.

13 Recaséns Siches, Tratado General de Filosofia del Derecho, p. 259. 
to, el mismo que no ha contribuido a la clarificación de lo que constituye la persona para el derecho.

\subsection{La persona como tema de diversas disciplinas del saber}

Una de las causas que contribuyen a la confusión reinante en cuanto al significado de persona es que ella no sólo es materia de indagación e interés para el derecho sino que también lo es para otras diversas disciplinas del saber humano. Nuestras primeras apreciaciones sobre el asunto, que datan de los años cuarenta del siglo pasado, nos llevaron a comprobar dicho aserto ${ }^{14}$. A las preocupaciones de los juristas habría que agregar, por consiguiente, aquella propia de los teólogos, de los filósofos, de los psicólogos, de los sociólogos, de los antropólogos, entre otros. Es decir, que el problema en torno a la persona no era propio ni exclusivo de la disciplina jurídica.

Lo expuesto explica el que Luis María Estibalez afirmara, en la década de los años cincuenta del siglo pasado, que el concepto de persona es "uno de los más llevados y traídos en las ciencias del espíritu» y uno de lo pocos que tienen tanta importancia y que suscitan tantas discusiones ${ }^{15}$. Gómez Arboleya, unos años antes, había sostenido, dentro de la misma línea de pensamiento, que la noción de persona es uno «de los grandes temas en que tienen que hablar a la par la teología, la metafísica del hombre y la teoría jurídica» ${ }^{16}$.

Son pues muchos los intereses así como las particulares visiones de las diversas disciplinas del saber que confluyen en torno a la persona. Ello no favorece el logro de una concepción unitaria de la misma.

\subsection{Carácter jusfilosófico de la indagación a emprender}

Otra causa de la confusión antes anotada, por su importancia e indiscutible jerarquía, es el que la cuestión concerniente a la naturaleza y signi-

14 Carlos Fernández Sessarego, La noción juridica de persona, segunda edición, 1968, p. 18.

15 Luis María Estibalez, En torno a la persona, Estudios de Deusto, vol. III, Bilbao, 1955, p. 67.

16 Enrique Gómez Arboleya, Sobre La noción de persona, Revista de Estudios Politicos, vol. XXII, N47, Madrid, 1949, p. 104. 
ficación de la persona es un tema reservado a la reflexión -al menos, primariamente- de los filósofos del derecho. La tarea de éstos es, precisamente, encontrar respuestas a los más hondos y radicales problemas relativos al ser humano sobre la base de los aportes de la filosofía general. De ahí que sea comprensible su angustia existencial por descubrir su propio hontanar.

La filosofía es un trance vital, una faena personal en la que se involucra aquel sujeto para el cual aparece como "problema" el saber de ultimidades, tales como aquellas referentes al ser del derecho o al ser de la persona humana. La Historia de la Filosofía es, como muy bien lo señala Julián Marías, "la dramática historia de esa pretensión humana» ${ }^{17}$ por encontrar la verdad radical. La verdad que consiste en saber quién soy yo en cuanto persona.

Decimos que desentrañar el significado de lo que es la persona es tarea de jusfilósofos porque los juristas o científicos del derecho no se han puesto ni siquiera aún de acuerdo sobre una concepción única, mayoritariamente aceptada, de lo que sea el derecho. Estimamos que ambas cuestiones, la del derecho y la de la persona, están esencialmente ligadas en tanto que si no se comprende lo que es la persona tampoco será posible entender la naturaleza y función del derecho.

Si bien nos reservamos volver sobre dicho cardinal asunto, cabe apuntar desde ahora y con Zubiri, que toda ciencia se refiere siempre a un objeto más o menos determinado "con el que el hombre se ha encontrado ya». Es decir, a cada ciencia corresponde un objeto a conocer y estudiar. De ahí que «si la presunta ciencia no posee claridad previa acerca de lo que persigue - es decir, sobre cuál sea su objeto - es que aún no es ciencia» ${ }^{18}$. Cualquier titubeo en este punto, como lo anota el citado filósofo español, "es signo inequívoco de imperfección".

Si nos atenemos a lo expresado por el filósofo hispano, comprobamos que el padecimiento de la ciencia jurídica es que no tiene suficientemente claro -o al menos, no lo ha tenido- cuál es el objeto propio de su conocimiento y estudio. Ello nos lleva a preguntarnos, una y otra vez, por el objeto de la disciplina. Y, cuando nos formulamos esta interrogante y nos

17 Julián Matías, Introducción a la Filosofía, Manuales de la Revista de Occidente, Madrid, 1947, p. 14.

18 Xavier Zubiri, Naturaleza, Historia, Dios, Editorial Poblet, Buenos Aires, 1948 , p. 135 . 
ponemos a reflexionar sobre el tema, surgen ante nosotros tres objetos diferentes, aunque esencialmente relacionados, que pretenden constituirse en el «objeto» del derecho. Nos referimos a la vida humana social -el ser humano en relación-, los valores y las normas jurídicas ${ }^{19}$.

Históricamente, diversas corrientes de pensamiento han hecho de alguno de tales objetos el «objeto" propio del conocimiento y estudio de la disciplina jurídica. Nos referimos, en particular, a las unidimensionales visiones que sobre el tema tienen el jusnaturalismo, el normativismoformalista y el sociologismo realista. Ante el panorama que nos ofrece la historia de nuestra disciplina cabe preguntarse, no sin cierta perplejidad, cuál de aquellos tres objetos es «el objeto» del derecho o es que, por el contrario, resultaría posible que una disciplina del conocimiento tenga simultáneamente tres objetos de estudio.

El tema, en última instancia y como está dicho, es de índole filosófico antes que jurídico. Por ello la pretensión de esclarecer lo referente a la noción de persona se constituye como una actitud, como una amorosa y anhelante vocación por aprehender ultimidades, por encontrar certidumbres radicales y primarias. Es decir, dicha actividad es la propia del filosofar en cuanto se trata de una actitud inquisitorial tras un objeto ${ }^{20}$.

19 Esta preocupación nos asaltó desde que éramos estudiantes de derecho. Nos desorientaba y nos inquictaba el escuchar o leer las diversas posiciones que existían sobre un tema que, en cuanto se constituía como una ciencia, debería tener claro cuál era su objeto. Este primer problema, con el que nos tropezamos siendo estudiantes nos motivó a cuestionar las respuestas que se daban, por insuficientes o incompletas, y a buscar por nuestros propios medios una solución que aquietara nuestra inquietud en cuanto a saber cuál era el objeto de la ciencia que estudiábamos y a la cual le dedicaríamos toda nuestra vida $y$, a la vez, nos permitiera tener una base firme para futuros desarrollos. Resultado de esta apetencia jusfilosófica fue el que nos dedicáramos siendo estudiantes a esta ambiciosa y audaz tarea. Su resultado fue nuestra tesis para obtener el grado de Bachiller en Derecho en la Universidad Nacional de San Marcos de Lima intitulada Bosquejo para una determinación ontológica del Derecho, la misma que fuera presentada en 1950. En ella se llegó a la conclusión de la tridimensionalidad del derecho, es decir, de una teoría que estimaba que el derecho es una disciplina en la cual interactúan dinámicamente tres objetos: vida humana social, valores y normas jurídicas. De esta interacción dinámica surgía el concepto "derecho". Al tema nos referiremos más adelante.

20 Carlos Fernández Sessarego, Bosquejo para una determinación ontológica del Derecho, tesis para optar el grado de Bachiller en Derecho, Lima, 1950 y en La noción juridica de persona, pp. 16-17. 
Como señalaba García Bacca, «ser filósofo es nacer condenado a perpetuidad al trabajo forzado de pensar ${ }^{21}$. Kant, en la Crítica del juicio, complementa esta sentencia al señalar los tres atributos que distinguen al filósofo: «pensar por sí mismo, enterándose de lo que piensan los demás, sin incurrir en contradicción».

El conocimiento científico es, por su propia naturaleza, parcial y fragmentario. Aborda el conocimiento de los objetos del mundo tal como se presentan ante nosotros. La ciencia, por ello, vale para dar razón de los entes que están bajo nuestra escrutadora mirada más no para brindar una respuesta sobre la "entidad» en sí misma. El conocimiento científico se limita al conocimiento del ente sin preguntarse por el «ser» del ente. Esta última tarea es, precisamente, aquella propia de la filosofía.

La ciencia jurídica necesita fundamentarse, inquirir no sólo por cuál es el ente u objeto de su conocimiento y estudio sino que también requiere aproximarse al conocimiento del ser de su objeto, así como discutir sobre las vías epistemológicas para aprehenderlo. El derecho necesita dar una razón primaria de su existencia y de su sentido. Es aquí donde aparece la filosofía para hacerse cargo de esta problemática. El científico del derecho, el jurista, no se pregunta normalmente por los supuestos del derecho. Se reduce a recibir de la jusfilosofía estos materiales, como algo dado y, a partir de ellos, desarrolla su trabajo dogmático. Esto no obsta, por cierto, para que los juristas recusen o cuestionen tales materiales si ellos no le ofrecen respuestas satisfactorias a sus inquietudes científicas ${ }^{22}$.

De todo lo expuesto se desprende, como conclusión, que el tema dedicado a desentrañar en última instancia el significado de la persona "trasciende, por su envergadura y características peculiares, el ámbito preciso de las diversas ramas del derecho para situarse en el plano de la filosofía del derecho ${ }^{23}$.

21 Juan David García Bacca, Invitación a filosofar, Fondo de Cultura Económica, México, 1940, p. 1.

22 Carlos Fernández Sessarego, El derecho como libertad, segunda edición, Universidad de Lima, Lima, 1994, pp. 5-6.

23 Carlos Fernández Sessarego, La noción juridica de persona, segunda edición, 1968 , p. 21. 


\subsection{La cuestión etimológica}

Acrecienta la confusión en cuanto al significado de la persona el origen etimológico mismo del vocablo y su sentido. Se discute si dicho origen se encuentra en el griego ${ }^{24}$, en el latín o en el etrusco. Según Stowasser, citado por Gómez Arboleya, la voz provendría de un participio, personatus, a, um, del verbo personare, que significaba revestirse o disfrazarse y que derivaba de una voz que se encuentra en Plauto: sona. Esta interpretación es acogida por Walde en su Diccionario Etimológico Latino ${ }^{25}$.

Modernamente se suele acoger mayoritariamente la tesis sostenida por Skutsch para quien la palabra "persona» tendría su origen en la voz persu proveniente del etrusco. Fundamenta su tesis en el hecho que, visitando la necrópolis de Cornete Tarquinii, halló la inscripción phersu al lado de dos personas enmascaradas. Considera que del etrusco pasó al latín en virtud de las conexiones existentes entre el teatro romano y la cultura etrusca ${ }^{26}$.

Francesco Ferrara reproduce la interpretación de Gavio Basso, referida por Aulo Gellio, que hace derivar la expresión «persona» del vocablo personare que significaba "resonar». Al admitir Ferrara que la expresión es equívoca $y$, por lo tanto, «susceptible de varios significados", deja constancia que la investigación glosológica es "auún bastante oscura», a pesar de lo cual estima que la indicada derivación es la más probable ${ }^{27}$.

24 La procedencia del griego es sostenida por Breal e Bailly en su Dictionnaire étimologique latin, 1866, p. 260 asi como por Klotz en su Diccionario manual de lengua latina. Esta misma posición es asumida por Fadda en su libro Diritto delle persone e della famiglia, Napoli, 1910 , p. 8, para quien dicha palabra pertenece al griego y significaba "máscara".

$25 \mathrm{Al}$ respecto, ver Carlos Fernández Sessarego, La noción juridica de persona, segunda edición, 1968 , p. 52.

26 Carlos Fernández Sessarego, La noción juridica de persona, op. cit., p. 52. Esta concepción es asumida por Pierre Ruffel, citado por Eugene Duthoit en su libro $L a$ personne humaine en péril, que transcribe Orgaz en Persona individual, p. 9. Para Ruffel "persona" deriva del etrusco phersu.

27 Francesco Ferrara, Teoría de las personas juridicas, Editorial Reus, Madrid, 1947, 1929 , p. 313 y ss. 


\subsection{Confusión histórica sobre la significación del vocablo "persona"}

La confusión en cuanto al significado de la persona se acentúa si consideramos las diversas significaciones que se otorgaban en Roma a la palabra "persona». Así, para unos, el término se usó en el sentido de la «máscara” utilizada por los actores en el teatro para interpretar sus respectivos roles. Otros, en cambio, se referían con tal expresión a los personajes que eran por ellos interpretados, mientras que no faltaban quienes aludían con dicho vocablo a la "cualidad" o "función» desempeñada en la vida corriente $o$ al hombre, en general ${ }^{23}$.

Como se aprecia de lo expuesto, las significaciones otorgadas históricamente al vocablo "persona" eran discordantes.

En tiempos recientes, como lo apunta Recaséns Siches, un factor histórico que ha contribuido a enmarañar el tema relativo a la persona ha sido el haber confundido diversos problemas en torno a la persona, los que se han superpuesto, y que no han sido debidamente esclarecidos. De ahí que el autor pueda sostener que «seguramente se debe a esa indebida involucración de cuestiones el que, a pesar de la copiosa literatura jurídica producida sobre la persona, aparezca todavía este tema rodeado de equívocos y vacilaciones".

Los temas que según Recaséns Siches no han sido delimitados adecuadamente para su debido tratamiento son aquellos que tienen que ver con las respuestas a cuatro preguntas: qué es persona para el derecho, quiénes son los entes sobre los que recae la calificación de persona, cuál es la naturaleza o el ser del ente al cual el derecho denomina persona y a quiénes el derecho debería conceder la calificación de persona. De ellos nos ocupamos sistemáticamente en el parágrafo 10 de este trabajo.

Otro tema que históricamente ha contribuido a complicar la concepción jurídica sobre la persona ha sido, sin duda, el de la aparición en el escenario jurídico de aquella persona que los pandectistas llamaron "persona jurídica" para distinguirla de la persona "natural» que era la única auténticamente tal. La persona "jurídica» es, por contraste, una persona "artificial" creada por el derecho, aunque en realidad y más exactamente, por la dimensión formal-normativa del derecho. Así nos encontramos en el siglo XIX con dos personas, una real y otra artificial. Desentrañar el problema relativo a la "persona jurídica" es todavía un

28 Carlos Fernández Sessarego, La noción juridica de persona, op. cit., p. 54. 
tema pendiente aunque para el sector mayoritario de la doctrina resulte ser un tema por lo demás claro y, por tanto, un caso cerrado.

Para el sector mayoritario de la doctrina la persona jurídica es tan sólo un centro unitario ideal de referencias normativas. Una entelequia, una abstracción, una fantasmagoría. La persona jurídica se nos imagina como un castillo habitado por fantasmas, en el que nada tienen que hacer los seres humanos, las personas naturales, y los valores que otorgan sentido a sus vidas. Desde nuestra perspectiva propugnamos una concepción tridimensional de la persona jurídica que es una «organización de personas inscrita en un registro público», hecho por el cual se crea, por abstracción, un ser ideal que funge de centro unitario de atribución de derechos y deberes. Es decir, se establece un régimen jurídico especial para esta organización de personas, un régimen de privilegio sobre el cual, sin embargo, pende la espada de Damocles del denominado "abuso de la personalidad jurídica" que, de producirse, tiene como efecto la desestimación o extinción del régimen de privilegio establecido por la normatividad jurídica.

\subsection{Confusión entre los conceptos de "persona» y de "personalidad»}

Otro problema que a nuestro parecer ha complicado modernamente aún más la comprensión de lo que es la "persona» es el referido a la confusión producida entre este concepto y el de "personalidad". Estimamos que ha faltado un deslinde conceptual entre ambas nociones, así como entre la de "personalidad" y la de "capacidad". Es decir, que con el término "personalidad» se alude por muchos, indistintamente, tanto a la "persona» como a la capacidad que le es inherente. Es evidente que ello conduce a una innecesaria como peligrosa confusión en asuntos donde, por su importancia, debería imperar la claridad conceptual.

Un sector de la doctrina considera como sinónimos los conceptos de "persona" y de "personalidad" ${ }^{29}$. Por ello, los utiliza indistintamente para referirse al ente que es el sujeto de derecho, es decir, a la "persona». Así, numerosos autores para referirse a los "derechos de la persona", que es el sujeto de derecho, siguen refiriéndose a ellos con la expresión «de-

29 Entre los autores que identifican ambos conceptos rccordamos a Jellineck, entre otros. Kelsen, por su parte, identifica ambos conceptos pero a nivel estrictamente normativo. 
rechos de la personalidad». Es decir, estiman a la «personalidad» como titular de derechos y deberes, como sujeto de derecho. La persona es el sujeto de derecho, es decir, el ser humano. La personalidad es tan sólo la manifestación fenoménica de la persona, su exteriorización en el mundo, su peculiar manera de ser.

No obstante lo dicho, cabe señalar que un sector importante de la doctrina utiliza el concepto "personalidad" ya no para aludir a la "persona» sino más bien para designar a la "aptitud" que tiene el ente, que es «persona», para adquirir derechos y obligaciones. Es decir, a una aptitud abstracta que no es otra cosa que lo que se conoce como "capacidad de goce o de derecho" ${ }^{30}$. Así, Ferrara considera, entre otros autores, que "personalidad" es una cualidad jurídica que debe acceder a determinado sustrato que es la "persona». Para Ferrara ambos conceptos son diferentes, ya que, en sus propias palabras, no es posible confundir "el peso" con el "objeto pesado" ni el "color" con el objeto "coloreado". Es decir, Ferrara plantea una diferencia entre la cualidad abstracta o aptitud del ente y el sustrato, es decir, el ente en sí mismo ${ }^{31}$.

Estimamos que el concepto "personalidad" no puede sustituir ni al de "persona» ni al de "capacidad". En el primer supuesto no hay duda que "persona" es el "ente que cada uno es" $\mathrm{y}$ "personalidad" es la proyección del ente "que cada uno es» hacia el exterior, es decir, su manera de presentarse en el mundo. Cada una de las personas, bien lo sabemos, «es la que es y no otra». Esta identidad personal se aprehende, por lo demás y entre otras vías, a través de la "personalidad» o «manera» de ser persona. Pero esta "personalidad" es diferente del ente mismo que, mediante ella, se proyecta al mundo exterior, se expone ante la mirada de los «otros». De ahí que no cabe confundir el concepto "persona», que es el ente considerado en sí mismo, con el de "personalidad". Sus significaciones son diferentes.

De otro lado, concebir que el concepto "personalidad" significa la «aptitud" para ser sujeto de derecho carece de sentido pues sólo el ser humano es, por su propia naturaleza, el ente «capaz» de adquirir derechos y deberes. En otras palabras, el término "personalidad" es inútil, innecesario, pues el ente que es sujeto de derecho es el ser humano, la persona, y

30 Cabe citar a Aubry et Rau, Trabucchi, Ennecerus, Gangi, Coviello, Barassi, entre otros, como autores que identifican "personalidad" con "capacidad".

31 Francesco Ferrara, Teoria de las personas juridicas, p. 320. 
precisamente, por serlo tiene ontológicamente capacidad de goce. No es posible concebir al ser humano, en cuanto ser ontológicamente libre, carente de su inherente capacidad para proyectarse en el mundo, para convertir en actos o comportamientos sus más íntimas decisiones.

De ahí que la noción de "personalidad» no puede sustituir ni al «ente» que es sujeto de derecho, es decir, a la "persona", ni a la "capacidad" o aptitud que le es inherente. Si se es "persona» se es «capaz». La capacidad de goce pertenece a la naturaleza misma de la persona, no es un atributo o un agregado concedido por el ordenamiento jurídico. No se concibe persona alguna que no tenga plena capacidad de goce, es decir, que no posea naturalmente la «aptitud» para ser sujeto de derecho. El derecho no puede actuar sobre esta capacidad de goce pues ella pertenece a la esfera del ser mismo del hombre y, por lo tanto, su comprensión es de índole filosófica. Es decir, el derecho no puede limitar ni restringir ni suprimir la capacidad de goce que es, como está dicho, inherente al ser humano. Sólo la muerte acaba con la persona, con su ontológica libertad y su inherente capacidad conocida como de «goce».

El derecho, por consiguiente, no puede intervenir sobre la capacidad de goce, no puede limitarla ni restringirla mediante norma alguna. El derecho sólo puede, mediante el aparato formal-normativo, limitar o restringir la capacidad de «ejercicio» o de «obrar» más nunca la capacidad de "goce", impropiamente también conocida como capacidad "de derecho". Limitar la capacidad de goce es, como está dicho, un imposible ontológico ${ }^{32}$. En cuanto el ser humano es libre, es capaz de realizarse como tal, es decir, de convertir en acto sus decisiones a través de su inherente capacidad de goce. El ser humano, todos y cada uno de los seres humanos, tienen la innata capacidad de gozar de todos los derechos naturales que les corresponden en virtud de su propia calidad ontológica de ser humano. Todos y cada uno de los seres humanos tienen la misma capacidad de goce.

En todo caso, lo que podría identificarse conceptualmente son los términos de "personalidad" y de "capacidad de ejercicio" más nunca los de personalidad y capacidad de goce. No obstante lo cual, no vemos la

32 A este propósito ver Carlos Fernández Sessarego, Código civil peruano. Balance y perspectivas, Universidad de Lima, Lima, Tomo 1, 1995 y «La capacidad de goce ees posible su restricción legal’” en la revista "Cáthedra", Año 3, No5, Palestra Editores, Lima, 1999 y en Jurisprudencia Argentina, N6185, Buenos Aires, 15 de marzo del 2000 . 
necesidad de introducir un vocablo innecesario en el lenguaje jurídico, como es el de "personalidad", en sustitución de otro que ya cuenta con una designación apropiada y tradicional como es el de la «capacidad de ejercicio".

En un anterior trabajo, fechado en 1962, decíamos al respecto que " la "personalidad" no es una cualidad que se agrega al hombre como sustrato, sino que la personalidad, entendida como concepto, es la forma como se aprehende al hombre como sujeto de derechos y obligaciones» ${ }^{33}$. Es decir que, a través de la personalidad, logramos aproximarnos a la identidad de la persona.

Según nuestro parecer, por consiguiente, el concepto "personalidad» ni sustituye al "ente» o sujeto de derecho, que es nada más ni nada menos que el ser humano - jurídicamente designado "persona" -, ni a su capacidad inherente, conocida como "capacidad de goce". Es por lo anteriormente expuesto que, desde hace décadas, descartamos en nuestros trabajos jurídicos la utilización de la expresión "derechos de la personalidad", pues tales derechos, en nuestro concepto, no pertenecen ni se atribuyen a la "personalidad" sino al «ente que cada uno es», es decir, a la "persona" y no a su proyección en el mundo exterior. La "personalidad", por consiguiente, no puede erigirse en titular ni de derechos ni de deberes. $Y$ es que, como está dicho, el concepto personalidad, que tiene más un carácter psicológico que jurídico, no se refiere al ente persona sino tan sólo a su proyección mundanal, a su «manera de ser». De ahí que el Libro Primero del Código Civil peruano de 1984 se denomina «Derecho de las Personas» y no se designa, como ocurre en otros cuerpos legales, como "Derechos de la personalidad".

Por lo demás, en el texto del mencionado Libro Primero del Código civil peruano de 1984 no aparece la expresión «derechos de la personalidad". Lamentablemente, comprobamos que la confusión conceptual que, a nuestro parecer, existe entre "persona" y «personalidad» continúa aún vigente ${ }^{34}$, pues se sigue empleando con profusión tanto por la doctrina como por la jurisprudencia y por los textos legales.

33 Carlos Fernández Sessarego, La noción juridica de persona, op. cit., p. 185.

34 En el Proyecto de Código civil argentino de 1998 observamos, no sin natural preocupación por nuestra vecindad de larga data con la cultura jurídica y con los civilistas argentinos, que se sigue empleando la noción de "personalidad" como sinónimo de "persona". Sería interesante un repensamiento del tema a la luz de los aportes de la jusfilosofía. 
Como se aprecia de lo hasta aquí brevemente expuesto, no son pocas las causas que han contribuido a impedir que, hasta no hace mucho tiempo atrás, los juristas no pudieran acceder a un concepto, mayoritariamente aceptado, de lo que significa la persona para el derecho. Ciertamente que la enumeración de dichas causas no es excluyente, por lo que podrían existir otras que en alguna medida pudieran haber contribuido a la confusión que tradicionalmente ha imperado en cuanto a la cuestión relativa a la persona y que escapan a nuestra observación.

\subsection{Ser humano, persona, hombre, individuo}

Advertimos, finalmente, que una cuestión de índole conceptual-terminológica se añade a las causas o razones de la confusión, antes referida, en torno al concepto jurídico de "persona». Estimamos que dicho factor consiste en que no siempre se deslindan adecuadamente las sutiles fronteras que existen, a nuestro parecer, entre los vocablos "ser humano", «hombre», "persona», «individuo». Por lo general no se repara en la cuestión o, simplemente, al no hacer de ella un "problema" para nuestro conocimiento optamos, a menudo, por la simple vía de utilizar tales expresiones, o algunas de ellas, como sinónimos en el lenguaje común y hasta en el jurídico. No obstante, se advierte entre ellas matices diferenciales que deben ser tomados en consideración a fin de precisar los conceptos que trasuntan tales expresiones. En los próximos parágrafos intentaremos identificar cuáles son los matices antes aludidos, desde que consideramos que vale la pena intentar esclarecer sus diferencias o similitudes.

\subsubsection{Ser humano}

El término "ser humano" se atribuye a todos los entes de nuestra especie denominada, precisamente, "humana». Desde esta perspectiva, los «humanos" somos animales mamíferos -como el chimpancé, el delfín, el perro o el caballo- que estamos dotados de ciertas características que nos hacen diferentes al resto de los animales mamíferos.

Por siglos se consideró que la diferencia entre el ente "ser humano" y el resto de animales mamíferos era que aquél estaba dotado de «razón» mientras que éstos, por el contrario, carecían de ella. Así lo aprendimos 
en la escuela ${ }^{35}$ y podemos comprobar que aún se sigue repitiendo en numerosos ambientes de la sociedad en contraste con los hallazgos que sobre el particular nos muestra la filosofía de la existencia. En cuanto animal mamífero el «ser humano" pertenece, como todos los animales, vegetales y minerales, a la naturaleza.

Los entes «humanos» somos, desde el punto de vista somático o biológico, seres "naturales». Compartimos, por ello, los instintos propios de nuestra especie de animales mamíferos, como los concernientes al comer o al reproducirse. El ser humano, en cuanto tal, está sujeto a todos los condicionamientos que provienen de la naturaleza. Como nos lo recuerda Mounier, nuestras ideas y nuestros humores son modelados por "el clima, la geografía, mi situación en la superficie de la tierra, mis herencias, y más allá, acaso por el flujo masivo de los rayos cósmicos». A estas influencias se les añaden todavía, dice Mounier, determinaciones psicológicas y colectivas posteriores ${ }^{36}$.

\subsubsection{Ser humano y "persona»}

No obstante lo dicho, sin dejar de ser un animal mamífero perteneciente a la naturaleza, el "ser humano", a diferencia de los demás animales mamíferos, posee un plus, un algo más, que constituye su ser, que es lo que conocemos como el espíritu de la libertad. La libertad constituye el núcleo existencial del "ser humano». De ahí que el «ser humano» no se reduzca a pura naturaleza -exclusivamente a la materia- sino que es, simultáneamente, un ser «espiritual». El "ser humano» trasciende la naturaleza. Es el espíritu de la libertad, y no solamente la razón, lo que caracteriza al "ser humano" y lo hace distinto de los demás entes del mundo.

$\mathrm{El}$ "ser humano" resulta así una unidad indisoluble, inescindible, entre lo que es su esfera psicosomática -su soma y su psique- y su centro existencial que es el espíritu de la libertad. A este ente, que es el «ser humano", se le designa filosóficamente como "persona». Con la expre-

35 Intuimos que por lo menos algunos mamíferos como el chimpancé, por ejemplo, están dotados de cierta elemental racionalidad. Este mamífero, como lo ha descubierto recientemente la ciencia, tiene un $90 \%$ de genes comunes con el ser humano. Los científicos están llegando a esta conclusión, por lo que es hasta ahora una simple intuición de nuestra parte tendría el aval científico requerido.

36 Emmanuel Mounier, El personalismo, Editorial EUDEBA, Bucnos Aires, 1962 , pp. 12-13. 
sión "persona" se quiere significar, precisamente, que el ser humano, sin dejar de ser un animal mamífero, es decir, un ente perteneciente a la naturaleza, es un ser simultáneamente espiritual cuyo centro o núcleo existencial es la libertad. Los demás mamíferos puede ser que posean, en algunos niveles, cierto grado de racionalidad, pero no son seres libres, seres espirituales.

El ser libre hace al ser humano responsable de sus actos. No se concibe la libertad sin responsabilidad. Tal vez ello mueva a muchos a renunciar libremente a actuar movido por sus propias decisiones $y$, más bien, someterse a los dictados de un tercero, ya sea un progenitor, un maestro, un jefe, un caudillo. En este caso se produce el fenómeno psicológico de la llamada "transferencia de culpa», mediante el cual el ser humano evita los estragos de sentirse responsable.

Los animales mamíferos, por ser tales, responden a sus instintos, mientras que los seres humanos, en cuanto seres «libres», son capaces de administrarlos. Risueñamente podemos decir al respecto que los animales no hacen huelgas de hambre ni dejan de comer para bajar de peso. Ellos están absolutamente condicionados por sus instintos. El ser humano, sin dejar de poseer instintos, los sublima, los administra. Ello es posible en tanto ser libre, no obstante estar sometido a numerosos condicionamientos.

Como anota Mounier, en tanto el ser humano pertenece a la naturaleza, el espiritualismo es de suyo insuficiente para dar cuenta cabal de lo que es el ser humano como lo es también el materialismo. De ahí que sostenga que «el espiritualismo y el moralismo son impotentes porque descuidan las sujeciones biológicas y económicas». Pero, a continuación agrega, que también «lo es, y en igual medida, el materialismo, por la razón inversa». El «ser humano», en cuanto "persona», no es puramente animal, parte de la naturaleza, sino también un ser espiritual cuyo centro existencial es la libertad. Justamente, como está dicho, es esta «libertad» la que diferencia radicalmente al ser humano de los demás entes de la naturaleza.

El «personalismo», que es una filosofía humanista, se hace cargo del universo de la persona, tal como ella es. Esta corriente de pensamiento, si bien entronca en una larga tradición, sólo se desarrolla, tal como actualmente la aprehendemos, en el siglo XX. Es sorprendente que se haya esperado tantos siglos para que los hombres de pensamiento, los filósofos, desviaran su escrutadora mirada, original y tradicionalmente cen- 
trada sobre el ser de los entes del mundo, para fijarla en ellos mismos, en el ser humano. De ahí que Mounier sostenga que «el personalismo no es un espiritualismo; muy por el contrario, aprehende cualquier problema humano en toda la amplitud de la humanidad concreta, desde la más humilde condición material a la más alta posibilidad espiritual» ${ }^{37}$. El personalismo, como lo hemos puesto de manifiesto, nos ofrece una visión completa, totalizadora, de lo que es la persona. Ciertamente, hasta donde ello es posible en tanto el universo personal es totalmente inabordable. La cuota de misterio que encierra el ser humano no ha sido aún puesta de manifiesto y difícilmente lo será -tal vez sea más preciso decir que ello deviene en un imposible- desde que la libertad supone impredicibilidad. En el ser humano, por ser libre y creador, existirán siempre conductas o comportamientos inéditos, que no se pueden predecir.

De lo hasta aquí expuesto podemos concluir que todo «ser humano», en cuanto ser libre y espiritual, es "persona", así como que no existe "persona" alguna que no sea un "ser humano». Con el vocablo "persona" se describe a un ser que, sin dejar de ser parte de la naturaleza, es también, radicalmente, un ser libertad. Esta realidad espiritual hace que al ser humano se le defina como "persona». Y este término, de raíz filosófica, ha sido asumido para referirse al ser humano no sólo por el derecho sino por un conjunto de disciplinas que centran en él su estudio. Es el caso, entre otros de la Psicología, la Antropología, la Sociología.

\subsubsection{Hombre y «ser humano»}

Lo dicho nos lleva a comprobar que el «ser humano», aprehendido como una indisoluble unidad psicosomática sustentada en la libertad espiritual resulta ser, desde una perspectiva filosófica -que no deja de ser realistauna "persona». Esta es, por lo demás, la realidad que designamos comúnmente como "hombre». Con la expresión «hombre» identificamos comúnmente al "ser humano", a la "persona". Es decir, que tales conceptos se utilizan indistintamente, como sinónimos, en el lenguaje común, por lo que el hombre es un ser humano, el hombre es una persona.

Frente al empleo de la expresión «hombre», dentro de los alcances conceptuales antes anotados, debemos considerar que, en la realidad de

37 Emmanuel Mounier, El personalismo, p. 15. 
la vida, la especie humana, como bien lo sabemos, se compone tanto de "hombres" como de "mujeres", por lo que resulta impropio e inadecuado, designar a la mujer con el concepto genérico de «hombre». El hombre, como la mujer, son igualmente seres humanos, más precisamente, personas. Es decir, que bajo la expresión "ser humano" se comprende tanto al hombre como a la mujer. En otros términos, el concepto genérico es "ser humano" y el específico es tanto el de "hombre" como el de «mujer», que equivalen, respectivamente, al macho y a la hembra de las especies animales.

La expresión «hombre» resulta, por lo dicho, insuficiente para aproximarnos a la realidad que designamos como «ser humano». En efecto, el "ser humano", como está dicho, no se reduce a los hombres -que son los machos de la especie humana- sino que el concepto, dada su amplitud, comprende también a las mujeres, las que constituyen tan sólo un género diferente. El pertenecer tan sólo a un género diferente hace que sea inadecuado que a la mujer se le identifique con el concepto «hombre». En cambio, bajo el genérico concepto de "ser humano" se comprende tanto a unos como a otras.

\subsubsection{Individuo y "persona"}

Con el empleo del término «individuo» se designa, comúnmente, a un determinado "ser humano", a una sola "persona». El concepto «individuo» carece, por consiguiente, de carga ideológica alguna. Significa simplemente un número, designa la unidad. Es, por ello, una expresión puramente cuantitativa. Podemos decir, así, que «individuo» resulta ser un término neutro, carente de significación filosófica, pues con su utilización no se da cuenta de la naturaleza del «ser humano» en cuanto "persona». Su empleo, por tanto, sólo significa que nos hallamos frente a un cierto "ser humano", a una determinada "persona".

Algunas veces, precisamente, por la neutralidad filosófica inherente al concepto «individuo", se le utiliza en el lenguaje ordinario o común en sentido peyorativo. Se quiere significar, en el fondo, que "ese» individuo al cual nos referimos carece de la calidad de persona o de algunas de sus características positivas. Es decir, que su valor se reduce tan sólo al de constituir una unidad. 


\section{La persona en la concepción tradicional de los juristas}

Consideramos de interés, antes de afrontar el tema relativo a la relación entre «sujeto de derecho" $\mathrm{y}$ "persona», apreciar sintéticamente como se ha tratado por los juristas el problema referente a la naturaleza de la persona para el derecho en la historia reciente ${ }^{38}$.

\subsection{Posición formalista sobre la persona}

En cierto tramo de la historia, cuando los juristas de formación normativista-formalista consideraban que el derecho se reducía a la normatividad, es decir, al ordenamiento jurídico positivo, el concepto de persona -es decir, el de sujeto de derecho- emergía, necesariamente, de dicho ordenamiento ${ }^{39}$. Si el derecho, según el positivismo formalista, es un sistema de normas, es evidente que el tema relativo a la "personaw tiene que desarrollarse en el mero campo de la normatividad. Es ahí donde, según la concepción formalista del derecho, deberíamos encontrar a la persona. Cabe advertir que como la norma es un objeto ideal, la persona ha de reducirse, también, a la misma categoría objetal. Es decir, la persona es para el formalismo jurídico una construcción lógico-for$\mathrm{mal}^{40}$. Así, Hans Kelsen encuentra sistemáticamente que la "persona" no es sino un conjunto de normas. En sus propias palabras, la persona es «una expresión unitaria personificadora para un haz de deberes y facultades jurídicas, es decir, para un complexo de normas" ${ }^{41}$.

Guillermo A. Borda anota al respecto que, dentro de dicha corriente de pensamiento, la verdad axiomática y elemental de que el hombre es la persona natural o física, ha quedado «esfumada en la doctrina moderna -sobre todo después de las enseñanzas de Kelsen- por un abuso en el

38 Sobre el tema ver Carlos Fernández Sessarego, La noción juridica de persona, op. cit., p. 93 y ss.

39 Ibid, p. 95 y ss.

40 En esta línea de pensamiento se sitúa Ferrara, quien sostiene que persona es «un concepto puramente formal que no implica ninguna relación de corporalidad o espiritualidad en el investido" y que es "una cualidad abstracta, ideal, proporcionada por la capacidad juridica y no resultante de la individualidad corporal y psíquica”. Francesco Ferrara, Teoria de las personas juridicas, Editorial Reus, Madrid, 1929, pp. 318-319.

41 Hans Kelsen, La teoria pura del derecho, Editorial Losada, Buenos Aires, segunda edición, 1946, p. 83. 
desarrollo lógico del concepto $»^{42}$. La persona, para el profesor argentino, no es un simple centro ideal de imputación de normas, representa una unidad de una pluralidad de normas. Es decir, que el derecho, en tanto sistema de normas, no crea a la persona.

Ferrara, uno de los más lúcidos expositores de la posición formalista sobre la persona, considera que ésta, sea individual o colectiva, no es una realidad, un hecho, sino una categoría jurídica formal. Ferrara distingue el hombre o ser humano, en tanto individuo, que es para él una realidad teológica-filosófica, de lo que es "persona» en cuanto cualidad abstracta, ideal, proporcionada por la capacidad jurídica y «no resultante de la individualidad corporal y psíquica». Si la persona es una entidad ideal, una entelequia, que se halla en el tiempo más no en el espacio, no existe dificultad alguna para que esta categoría formal y abstracta sea otorgada a entes que no sean hombres. Es así que la historia nos demuestra, según Ferrara, el que en Roma se concedió esta categoría de "persona» a algunos dioses como es el caso de Apolo o Júpiter y que, en los derechos orientales, se reconocía como dotados de esta categoría a las plantas, a los animales, a las cosas inanimadas ${ }^{43}$.

Para los juristas que aceptan la concepción formalista del Derecho ${ }^{44}$ $y$, por ende, la de la persona, el ordenamiento jurídico positivo puede, como está dicho, conceder esta categoría formal a cualquier ente de la naturaleza, sea o no el ser humano. De ahí que "persona» podía ser, indistintamente, el ser humano o Incitatus, el caballo de Calígula que fuera designado Cónsul. Todo depende, por consiguiente, del ordenamiento jurídico positivo. Del mismo modo, el ordenamiento jurídico positivo podía "despojar" de la calidad de persona a ciertos seres humanos. Es el caso de los esclavos. C iertamente, este despojo es un imposible ontológico pues todo ser humano es, de suyo, "persona». Lo que sucede en el caso de los esclavos es que se le limitaba su capacidad de ejercicio, más no podía negársele por una simple norma, legal o consue-

42 Guillermo A. Borda, Tratado de Derecho Civil Argentino, Perrot, Buenos Aires, 1955, pp. 205-207.

43 Francesco Ferrara, Teoria de las personas juridicas, p. 332.

44 Dentro de los autores que aceptan la tcoría formalista sobre la persona -aparte de Ferrara y Kelsen- podemos citar a Lehman, Von Thur, Josserand, Michoud, los Mazeaud, De Diego, De Cupis, Di Semo, Gangi, Rotondi, Barassi, Bevilacqua, Salvat, entre otros. Todos ellos, o casi todos, desarrollan sus trabajos jurídicos en la primera mitad del siglo XX o en los últimos del siglo XIX. 
tudinaria, su calidad de ser humano, de persona $y$, por consiguiente, su inherente capacidad de goce $^{45}$.

\subsection{Visión realista}

Frente a la concepción formalista de la persona se alzó, históricamente, aquella que denominamos «realista». Para esta corriente de pensamiento ${ }^{46}$ la persona no es un producto o resultado del ordenamiento jurídico positivo, es decir, una categoría abstracta y formal, sino que ella se constituye como una realidad natural, como un objeto real ${ }^{47}$. De ahí que no hay más persona que el «ser humano» en cuanto tal. Esta realidad debe ser necesariamente reconocida por la normatividad como una situación preexistente. La normatividad, debe adecuarse a la realidad, a la experiencia.

Entre los autores que se afilian a una concepción realista sobre la persona podemos citar a Colin y Capitant, quienes identifican a la persona con los seres humanos. Estos son, para ellos, los sujetos del derecho, las personas propiamente dichas. Estas personas, "con dudosa exactitud llamadas físicas", son «las únicas verdaderas personas». No obstante lo dicho, se presenta una incongruencia en su pensamiento por cuanto, a pesar de lo expresado, los autores le otorgan dos significaciones al concepto "persona" una de las cuales, contradictoriamente, se resuelve en una abstracción desde que se le considera, desde el punto de vista del papel ${ }^{48}$ que ella desempeña en la sociedad, como actora o protagonista de la vida social.

45 Obviamente, no compartimos esta tesis pues todo ser humano es persona. En el caso de los esclavos lo único que sucede - y no es poca cosa - es que se le limita su capacidad de ejercicio en diversa medida. Han habido momentos en la historia donde la limitación era muy marcada. En otros momentos dicha limitación era menos exigente. Es decir, que el problema de la esclavitud no es uno que tiene que ver con la privación de la categoría de persona de los denominados esclavos sino tan sólo de una limitación de su capacidad de ejercicio. Ciertamente, la capacidad de goce del esclavo, como la de cualquier ser humano, se mantenía intacta.

46 Se alinean en esta posición Colin y Capitant, Planiol, Renard, Borell, Valverde y Valverde, Ruiz Jiménez, Rodríguez Arias-Bustamante, Carnelutti, Ruggiero, Dusi, Gonella, Borda, Hübner Gallo, entre otros.

47 La forma es un objeto ideal en cuanto está en el tiempo más no en el espacio. Los objetos reales, por el contrario, se hallan en el tiempo y en el espacio.

48 Ambrosio Colin y H. Capitant, Curso Elemental de Derecho Civil, Tomo I, Editorial Reus, Madrid, 1941, p, 132. 
En el pensamiento de Borell, se rechaza la tesis de que la persona sea sólo un concepto jurídico y que, por lo tanto, no implique ninguna condición de corporalidad o espiritualidad. Por el contrario, sostiene que la persona es el hombre, el ser humano en cuanto tal, con independencia del reconocimiento del derecho objetivo. La calidad de persona es inherente al ser humano ${ }^{49}$. En este mismo sentido se pronuncia Gonella al afirmar "que la persona es inseparable del hombre, y es tal en el hombre», es decir, su naturaleza es humana ${ }^{50}$.

\subsection{Teoría ecléctica}

Una tercera posición sobre la persona para el derecho, que podemos designar como ecléctica, sostiene que los autores que se adhieren a la tesis formalista y a la realista sobre la persona consideran sólo un aspecto de una misma realidad. Así, la teoría realista incide en el aspecto éticojurídico del problema con prescindencia del aspecto dogmático y la teoría formalista se preocupa tan sólo del ángulo normativo dejando de lado la realidad existencial ${ }^{51}$. Para los autores que se afilian a esta posición resulta necesario armonizar los puntos de vista parciales del realismo y del formalismo con el propósito de lograr una visión completa y no fragmentaria de una misma realidad.

Estimamos de interés glosar brevemente dentro de la concepción ecléctica la posición de dos juristas argentinos como son Spota y Orgaz, que escriben aproximadamente al finalizar la primera mitad del siglo XX. Es decir, cuando el tema sobre la naturaleza de la persona era de toda actualidad bajo un enfoque superado en la actualidad a partir de los hallazgos filosóficos del existencialismo.

Spota se pregunta al respecto si la persona es sólo una tesitura meramente formal, un centro al cual el ordenamiento jurídico imputa hechos y actos jurídicos, o sí, por el contrario, el concepto de persona exige la materialidad ínsita al hombre ${ }^{52}$. Estima que es preciso enunciar

49 Antonio Borell, Derecho Civil Español, Tomo I, Parte General, Bosch Editores, Barcelona, 1955, p. 105.

50 Guido Gonella, La persona nella filosofia del Diritto, Giuffré, Milano, 1938, p. 227.

51 Entre los autores que sc adhiercn a esta posición podemos citar a Orgaz, Dabin, Spota, Pugliatti, entre otros.

52 Alberto G. Spota, Tratado de Derecho Civil, Tomo I, Parte General, vol. 2, Depalma, Buenos Aires, 1948, p. 5. 
que el concepto de persona encierra un elemento formal y un elemento material. Y, clarividentemente, también inquiere sobre si dicha materialidad se puede también observar en las organizaciones humanas para alcanzar fines sociales. Es decir, como diríamos actualmente, si es propio de la naturaleza de la persona jurídica la organización de personas aparte del dato meramente formal y de los valores perseguidos por los miembros de dicha organización.

Para el tratadista argentino, cuyo pensamiento hemos glosado, no es suficiente la presencia del elemento formal para configurar el concepto jurídico de persona. Si esto fuera así, se trataría según el autor, de un pecado lógico. No basta afirmar, sostiene, que la persona es un mero centro ideal de imputación de derechos y deberes desde que no puede prescindirse del ente que «realmente» tiene la aptitud de ser dicho centro de imputación.

Orgaz, por su parte y con toda razón, considera que ninguna "cualidad jurídica» puede existir por sí misma sino que necesita de un soporte o sustrato real. Recordando el origen etimológico del término "persona», Orgaz recuerda que ella no es solamente el individuo humano, la colectividad, que representan el sustrato, ni tampoco lo es únicamente la cualidad abstracta (la "máscara»). Persona es el sustrato "con" la aptitud que le atribuye el ordenamiento juridico ${ }^{53}$.

\subsection{Concepción tridimensional de la persona}

Desde nuestro punto de vista las posiciones sobre la naturaleza de la persona antes referidas son parcialmente ciertas. Ello, desde que no nos proporcionan una visión completa de lo que es la "persona" para el derecho. En ninguna de tales tesis se refleja lo que es el derecho en la experiencia humana, es decir, la interacción dinámica entre vida humana social, valores y normas jurídicas. En las posiciones que hemos enunciado en precedencia se prescinde del elemento axiológico. Estimamos que cualquier trozo de la experiencia jurídica -y la persona lo es- se presenta, como está dicho, como una interacción dinámica entre los mencionados tres objetos. El derecho no se reduce a ninguna de tales dimensiones pero, como se ha sostenido, ninguna de ellas puede faltar cuando nos referimos al derecho, a cualquier institución jurídica. 
De ahí que debamos encontrar una noción de "persona" que armonice con la realidad del derecho. La respuesta la tenemos que hallar, por consiguiente, dentro de una concepción tridimensional de lo jurídico. La «persona» es el ser humano que, en cuanto libre, vivencia valores. En tanto coexistencial, su conducta intersubjetiva está normativamente regulada, por lo que se constituye en un centro de imputación de situaciones jurídicas subjetivas, es decir, de derechos y deberes. Encontramos así conjugados en la "persona" los tres elementos del derecho: la vida humana que es, los valores que realiza y otorgan sentido a su conducta y las normas que regulan la convivencia a través de la imputación de situaciones jurídicas subjetivas.

La "persona» es un ser humano viviente, que valora para proyectar su vida, situado en una relación jurídica con los demás, la que es regulada por normas jurídicas que le atribuyen una determinada situación jurídica subjetiva, es decir, un plexo de derechos y deberes.

\section{Sujeto de derecho y persona}

Sujeto de derecho, bien lo sabemos, es un ente al cual se le imputan situaciones jurídicas subjetivas, es decir, derechos y deberes. Y, como está dicho, en la doctrina generalmente se trata ambos conceptos como sinónimos en tanto no hay más sujeto de derecho que la persona -ya sea natural o jurídica- $y$, por consiguiente, toda persona es sujeto de derecho. ¿Sigue siendo esto exacto en la actualidad?. ¿Sólo la persona natural y la jurídica son los únicos sujetos de derecho?. ¿Y el concebido, y la organización de personas no inscrita, no son acaso sujetos de derecho?.

En la actualidad, a diferencia del pasado inmediato, no se suelen confundir, por lo general, las nociones de "sujeto de derecho" y de "persona». Ellas se distinguen solamente desde un punto de vista técnicojurídico, desde una perspectiva puramente formal. Aunque en la codificación comparada no aparece todavía otro sujeto de derecho que no sea la persona natural y la persona jurídica -por lo que sujeto de derecho y persona son conceptos que se superponen-, en los tiempos que corren se advierte una nueva tendencia con la que se pone de manifiesto una diferencia conceptual entre ambas nociones ${ }^{54}$. Esta tendencia tiene su fun- 
damento en la observación de la realidad, es decir en la experiencia jurídica, que es donde hallamos el derecho vivo.

En la experiencia jurídica observamos que no sólo actúan como sujetos de derecho -es decir, como entes a los que se atribuyen situaciones jurídicas subjetivas- la persona natural y la persona jurídica, como tradicionalmente se advertía, sino que en ella siguen actuando, desde tiempos remotos, la "organización de personas no inscrita» y el «concebido". Ello, ante la indiferencia de la codificación comparada. Es decir, la organización de personas "no inscrita" es aquel grupo o colectividad que, al igual que las antiguas collegia o universitas personarum, persiguen fines valiosos a través de una actividad en común. Esta organización de personas actúa en la realidad como si fuera una persona jurídica aunque, al no haberse inscrito en un determinado registro público, no goza del régimen especial con que se benefician las personas jurídicas. Así, por ejemplo, los miembros que la integran, a diferencia de aquellos que componen la persona juridica, son propietarios de los bienes que posee la organización así como, simultáneamente, responden por sus obligaciones.

La organización de personas no inscrita pasó al olvido ante el extraordinario invento de lo que conocemos como "persona jurídica", el mismo que históricamente se atribuye a la pandectística. Pero a pesar del explicable deslumbramiento que entre los juristas produjo tal invento, ello no significó, en la práctica, que la «organización de personas»que no era persona jurídica por no haber cumplido con la formalidad de una inscripción en un determinado registro público- dejara de estar presente y actuara como sujeto de derecho en la experiencia jurídica. Ello, no obstante el olvido de parte de los juristas y de su exilio del ordenamiento jurídico positivo.

Se tuvo que esperar la promulgación del Código civil italiano de 1942 para que se asumiera a nivel normativo y, consiguientemente se regularan en su texto, tanto las asociaciones como los comités «no reconocidos» (para nosotros, no inscritos) aunque en forma limitada. No se tuvo en cuenta, sin embargo, a la fundación no inscrita a la que sí se norma en el Código civil peruano de $1984^{55}$.

ciones no reconocidas" y a los comités que no son personas jurídicas (arts. $36^{\circ}$ a $42^{\circ}$ ). Su desarrollo es, sin embargo, limitado dado el momento histórico en que se redactó tal cuerpo legal.

55 Ver artículos $127^{\circ}$ a $129^{\circ}$ del Código civil peruano. 
En la actualidad podemos sostener, por consiguiente, que el concepto de "sujeto de derecho" es el ente al cual el ordenamiento jurídico atribuye situaciones jurídicas subjetivas, es decir, deberes y derechos. En la realidad, en la experiencia jurídica, el concepto formal de «sujeto de derecho" se refiere, siempre, al ser humano. Es decir, al ser humano en sus cuatro maneras de presentarse en el mundo, desde su concepción hasta su muerte.

Cuatro «maneras de ser" que son asumidas y reguladas por el derecho a través del ordenamiento jurídico. Es decir, como ser humano por nacer -concebido-, como ser humano nacido -persona natural-, como organización de personas sin inscribirse ni ser reconocida por el Estado y, finalmente, como organización de personas que, por el hecho formal de su inscripción, se convierte en lo que, impropiamente, se le designa como "persona jurídica». A la persona jurídica, en cuanto organización de personas que persigue fines valiosos se le conceden ciertos privilegios que supone el atribuirle un régimen de «excepción» que la sustrae de la regulación del derecho común que regula a cualquier otra organización de personas "no inscrita». En esto consiste el útil invento de la pandectística.

El régimen de "excepción", creado por ley para la concesión de ciertos privilegios no reconocidos a nivel del derecho común, se deja sin efecto -se desestima, suele decirse-cuando alguno o algunos o todos los miembros utiliza ilícitamente el «invento" concesorio de privilegios para el grupo humano que integra la persona jurídica. Es el caso que se conoce comúnmente como "abuso de la personalidad jurídica", aunque mejor sería decir mal uso de la "estructura formal" de la persona jurídica. Es también el caso del uso fraudulento de los mencionados privilegios.

En síntesis, el concepto de sujeto de derecho tiene siempre como correlato en la realidad al ser humano, a todos los seres humanos sin excepción. Sólo el ser humano, en cualquiera de sus cuatro «maneras de ser", es sujeto de derecho. Es decir, individual o colectivamente considerado. Ningún otro ente de la naturaleza es sujeto de derecho.

De lo expuesto se desprende, por consiguiente, que sólo lo que jurídicamente se alude como "persona" es sujeto de derecho. Es decir, la persona es sujeto de derecho en cuanto ser humano, en cualquiera de las mencionadas cuatro maneras de presentarse en el mundo. Aunque a nivel de la doctrina -al menos en la peruana-, por el momento, el término persona se reserva sólo para el ser humano nacido -persona natural-y 
para el ser humano que constituye una «organización de personas» inscrita y que, por este hecho, como está dicho, adquiere un estatuto legal de excepción. El concebido, sin embargo, es una persona por nacer, tal como se le reconoce en la doctrina y en la legislación argentinas. Sólo no se menciona como persona a la "organización de personas no inscrita", desde que el adjetivo de "jurídica" lo expropiaron los pandectistas para designar a la organización de personas «inscrita».

Esperemos que, tal como con acierto sucede en el Código Civil de Portugal, con el tiempo se resuelva el problema semántico que se ha creado por la "aparición» en el ámbito legislativo de dos nuevos sujetos de derecho. En efecto, en este Código se alude a dos categorías de personas, la individual y la colecriva. En la primera se comprenderían al concebido y a la persona natural $y$, en la segunda, a las dos organizaciones de personas antes mencionadas. Siguiendo esta posición, que nos pareció adecuada, propusimos adoptarla por lo cual, al ser aprobada originalmente por la Comisión de Reforma del Código civil de 1936, se incorporó al Proyecto de Código Civil de 1984. Lamentablemente, con posterioridad a dicho acuerdo se aprobó la Constitución Política de 1993 en la que se mantuvo la tradicional clasificación de persona natural y persona jurídica, por lo que tuvo que adecuarse el Proyecto en referencia a la Carta constitucional.

\section{La persona en la filosofía y en el derecho}

Si bien el tema de la persona es en última instancia, como se ha señalado, uno de carácter jusfilosófico, ello no significa por cierto que, sobre la base y los hallazgos de la filosofía del derecho, no exista un enfoque netamente jurídico de la persona.

¿Cuál es la diferencia entre ambos enfoques?. La Filosofía, en general, y la Filosofía del Derecho, en particular, se preocupan por aproximarse a la real y peculiar estructura del ente "persona". Su centro de interés es responder a la pregunta sobre el ser de la persona. Sobre qué es "persona». De ahí que cualquier posición que se adopte sobre la persona en el derecho ella debe enraizarse en la Filosofía General y en la Filosofía del Derecho. La persona que actúa en el derecho es la misma que nos presenta la Filosofía en cada momento histórico. Y decimos en "cada momento histórico" porque la respuesta sobre el ser atribuido a la per- 
sona por la Filosofía ha sufrido un vuelco histórico, el mismo que ha repercutido decisivamente en el enfoque jurídico sobre la persona como lo apreciaremos en su lugar. Con lo dicho queremos expresar, sintéticamente, que la persona es "el mismo ente» tanto en la Filosofía como en el derecho o como en cualquier otra disciplina del saber humano.

Es posible, no obstante lo dicho, distinguir un planteamiento específicamente filosófico de la persona de otro de carácter jurídico, aunque la base para el planteamiento jurídico sea de índole jusfilosófica. La búsqueda filosófica, como se ha precisado, tiende a determinar la naturaleza o estructura del ser humano mientras que al derecho le interesa la persona en cuanto «sujeto de derecho». En este mismo sentido, Guido Gonella manifiesta al respecto que, filosóficamente, la persona es considerada como «hombre» - como «ser humano» preferimos decirlo nosotros - mientras que en el campo del derecho se entiende por persona sólo al "sujeto de derecho" ${ }^{56}$. Es decir, que al derecho le interesa el ente "persona" en tanto es "sujeto de derecho". Es desde esta vertiente que nuestra disciplina se ocupa de la persona.

\section{El vuelco histórico sobre la concepción del derecho y la persona en la primera mitad del siglo XX}

La concepción tradicional sobre el derecho y la persona que poseía la Filosofía del Derecho sufre un impresionante vuelco -aún no debidamente valorado y comprendido por la falta de perspectiva temporal-en la primera mitad del siglo XX. Esta restauración filosófica, esta revalorización del ser humano, se debe a los hallazgos de la filosofía de la existencia a través del pensamiento de filósofos como Sartre, Heidegger, Marcel, Jaspers, Mounier, Zubiri, entre otros ${ }^{57}$. Es en este momento

56 Guido Gonella, La persona nella Filosofia del Diritto, p. 4.

57 Si bien es que en la primera mitad del siglo XX, sobre todo en el período comprendido entre las dos guerras mundiales, surge esta nueva concepción sobre el ser humano no podemos dejar de lado los atisbos que en el siglo XIX contribuyen a su formulación. Así, no podemos dejar de citar los nombres de algunos pensadores que establecen hitos importantes en el curso de la evolución del pensamiento filosófico sobre la persona. Es el caso, entre otros, de filósofos de la talla de Kant, Kierkegaard, Nietsche. 
histórico que se produce un decisivo aporte filosófico que permite una nueva comprensión de la naturaleza del ser humano que, necesariamente, repercute en una nueva visión del derecho. La raíz de esta novedosa concepción se encuentra en los postulados del Cristianismo cuando se afirma que la persona es un ser libre ya que, si no fuera así, no se comprendería el significado del pecado, del arrepentimiento, del perdón, de la redención.

«Derecho" y «persona», bien lo sabemos, son los dos conceptos básicos, medulares por fundamentales, cuya cabal comprensión es indispensable para iniciarse en el estudio de la disciplina jurídica. Si no se tiene clara su significación, es decir, sin saber en qué consiste cada uno de ellos, nos resultaría imposible sustentar una investigación seria y coherente, debidamente fundamentada, sobre la institucionalidad jurídica. Debe haber claridad sobre los cimientos que sustentan la construcción o el enjambre normativo así como se debe intentar eliminar, en lo posible, titubeos o dudas sobre el punto de partida, si se pretende asegurar el correcto resultado de la investigación jurídica a nivel dogmático.

Ambos conceptos, el de derecho y el de persona, se hallan esencialmente vinculados desde que el derecho es una exigencia existencial, una exigencia de la naturaleza humana. De ahí que no pueda concebirse la existencia de la persona sin la simultánea presencia del derecho ya que, siendo la persona un ser coexistencial -estructuralmente social-, no podría "convivir» - es decir, vivir con «otros»-sin reglas de conducta obligatorias $^{58}$, orientadas por los valores que otorgan un sentido, una razón de ser a la vida humana. Es imposible, por ello, imaginar o pensar a la persona, en cuanto ser humano, fuera de la sociedad, sin estar sujeta a reglas de comportamiento -morales, éticas, religiosas, jurídicas- que le permitan convivir, proyectar su vida, realizarse como persona dentro del bien común. Es decir, «ser lo que se decidió ser», dentro de los naturales condicionamientos que limitan y restringen el quehacer humano.

Si la persona y el derecho se exigen recíprocamente, desde que no existe una sin el otro y viceversa, es necesario precisar qué tipo de relación existe entre ambos conceptos, cuál es su modo de relacionarse. Cabe preguntarse, por ello, si ¿es el derecho algo exterior al ser humano o, por

58 Lamentablemente, quedaron atrás los tiempos en los que las reglas de conducta tenían un contenido religioso o moral. Es decir, los tiempos casi paradisíacos de la autorregulación. 
el contrario, forma parte de su propia estructura?. Por nuestra parte, estimamos que el derecho no es una simple superestructura sino que, por tratarse de una ineludible exigencia existencial, se constituye como parte de la estructura humana.

\section{Itinerario de nuestra indagación sobre el derecho y la persona a partir de los años cuarenta del siglo XX}

Tanto el tema concerniente al objeto de estudio del derecho como el de la naturaleza de la persona nos inquietaron tempranamente, desde que éramos estudiantes. A ambos le dedicamos, dentro de nuestras comprensibles limitaciones, nuestra preferente atención. Sentíamos la imperiosa necesidad de desentrañar su sentido, pues intuíamos que sin su cabal comprensión no nos sería posible adentrarnos con coherencia en la institucionalidad jurídica. Derecho y persona se erigían como dos incógnitas que para un estudiante de derecho era indispensable desentrañar.

De dicha inquietud, de tal intuición, nació una tenaz investigación por saber en qué consistía tanto el derecho como la persona y sobre cuál era la manera como se relacionaban. Estas indagaciones dieron origen a una trilogía de libros espaciados en el tiempo. Nuestras investigaciones y su cristalización en dichas obras no hubieran sido posibles sin el sustento que nos ofreció el rico bagaje tanto de la filosofía de la existencia como de la fenomenología de Husserl, del pensamiento de Carlos Cossio, Hans Kelsen y Luis Recaséns Siches, entre otros.

El primero de dichos libros, pensado en la segunda mitad de la década de los años cuarenta del siglo XX, encontró su expresión en la tesis que para optar el grado de Bachiller en Derecho fuera presentada en 1950 en la Universidad Nacional Mayor de San Marcos de Lima, con el título de Bosquejo para una determinación ontológica del Derecho.

Como con razón la calificó Carlos Cossio en un comentario aparecido en "La Ley» de Buenos Aires en el año de 1963, la tesis fue audaz y ambiciosa. Audaz, porque fue concebida en un momento histórico total y absolutamente dominado por el pensamiento normativista-formalista de Hans Kelsen ${ }^{59}$. Y, además, porque la persona que la había concebido

59 Se trataba de la audacia propia de un estudiante de Derecho que frisaba los veintiún años cuando inició su tarea de investigación. En el prólogo de la tesis se decía 
era tan sólo un estudiante de derecho. Ambiciosa, desde que ella pretendía nada menos que llegar a determinar el ser mismo del derecho, el objeto de su estudio disciplinario ${ }^{60}$. Y, agregaríamos, con la perspectiva que nos da el tiempo transcurrido, que ella tuvo un contenido profundamente crítico frente a las corrientes de pensamiento dominantes por aquel entonces.

No obstante lo expresado en el párrafo precedente, la audacia y la ambición antes aludidas estaban enmarcadas, como se decía en el prólogo de dicha tesis, dentro de la "plena convicción" de "nuestras limitaciones y deficiencias, teniendo presente, a cada paso, que la actitud moral del investigador -como parte del método- es la humildad, más tratándose de la indagación jusfilosófica que es movimiento callado, recóndito,

que ella era "producto de una inquietud nacida en los umbrales del aprendizaje del Derecho en los claustros de San Marcos. Inquietud que nos ha acompañado año tras año, siempre creciente, hasta la culminación de nuestros estudios en la Sección Doctoral". Conscientes de nuestras limitaciones sosteníamos que la tesis era "un esbozo de respuesta que se ensaya a través de páginas posteriores - y que en el fondo no es sino una muestra de algunos aspectos de la problemática del Derecho - pretendería compartir aquella actitud y estar grávido de la mentalidad contemporánca». Yagregábamos que "pretendería ser parto de inquietudes del hombre actual, vivencias juridicas desde la perspectiva histórica de nuestra época, tarea irrenunciable de una generación que vive tiempo presente». Nos rebelábamos contra lo que se nos enseñaba y leíamos en aquellos años de la década de los años cuarenta del siglo XX. Estábamos poseídos de un agudo sentido crítico. De ahí que apuntáramos en dicha introducción que se trataba de una "interrogante que nos asalta detrás de cada artículo del Código, que aparece furtiva con posterioridad a fragmentarias y dispares explicaciones de ciencia dogmática; multitud de opiniones, muchas contradictorias, otras asistemáticas, diseminadas en manuales y tratados que nos ofrecen cuestionables soluciones; ideas "encapsuladas", que pasan de generación en generación tratando de despejarla sin que se adopte ante ellas una actitud crítica: interrogante que nos angustia y nos motiva a darle respuesta a través de una propia meditación". Porque, señalábamos, se debe tener un afán por "decir lo que uno piensa, y porque es bueno que haya gente que piense y diga lo que piensa", como anota Leclerq, el filósofo de Lovaina. Y ello, "sin sentirse en la obligación de decirlo todo, de agotar la materia con ingenua pretensión".

60 Ambiciosa, en cuanto nuestra inquietud por saber era honda y radical, como la que hoy también es nuestra eterna compañera de viaje en nuestro ya extenso transcurrir existencial. Al respecto decíamos en el prólogo de la tesis que ella era "un pertinaz afán por encontrar una respuesta a la vieja y siempre nueva interrogante por el ser del Derecho; respuesta, que aunque provisional, nos proporcione una visión unitaria de la disciplina a la que ofrendamos cotidianamente nuestros más caros y preciados esfuerzos». 
personal». En la investigación que culminara en 1950, sosteníamos, «que lo que más importa es la actividad misma, en que consiste el filosofar, que las conclusiones a que se arribe o la pasiva repetición y acopio de opiniones ajenas». Estas opiniones ajenas son, "a través de la historia, incitación, estímulo, archivo de problemas y planteamientos». Ellas constituyen, decíamos, "soluciones que deben ser repensadas pero nunca muestrario de inertes adhesiones».

Con el citado trabajo juvenil nos proponíamos encontrar una respuesta unitaria «a la vieja y siempre nueva interrogante por el ser del Derecho». El trabajo significó una crítica a las respuestas unidimensionales, al racionalismo divorciado de la historia, a la deshumanización del Derecho, en síntesis. Se perseguía en dicho auroral trabajo el imprescindible «replanteo de los más importantes temas jusfilosóficos a fin de adecuarlos a los aportes de la filosofía última para aprovechar sus hallazgos y, sobre todo, su metodología". Se pretendía como tarea previa «el planteamiento nítido del hecho fundamental de la existencia, para insertar en ella al Derecho como una de sus formas radicales». Es decir, para concluir que el derecho es, primariamente, vida humana intersubjetiva. Vida humana que, después de ser valorada, se concreta en norma consuetudinaria, legal o jurisprudencial.

La tarea que concluyó en 1950 con la presentación de la citada tesis titulada, como está dicho, Bosquejo para una determinación ontológica del derecho, fue publicada 37 años después ${ }^{61}$ bajo el nombre de El dere-

61 La razón por la cual nos opusimos a los requerimientos de publicación del trabajo están anunciados en el prólogo cuando se expresa: «audaz nuestra ambición y vasto el tema, él trasciende el contenido de estas páginas y al resultado de nuestros esfuerzos. Quedan innúmeros problemas sin solución, otros apenas planteados o bosquejados, muchos ignorados. Ellos, si Dios lo permite, quedan pendientes como programa para el futuro, como proyecto de nuevos trabajos de los cuales el presente es sólo tímido anuncio y provisional punto de partida. Quizá en estas páginas se han producido muchos apasionados encuentros o reencuentros - con los grandes temas y las ideas matrices que habrán de ser desarrollados y profundizados con el devenir de los años. Ellas son testigo objetivado de múltiples tanteos, aproximaciones, jubilosos atisbos, falsas vías. $Y$, apenas terminadas, vislumbres de posibles rectificaciones". Esta era la impresión que teníamos del trabajo producido y, dentro de ella, se encuentra la razón por la que no considerábamos todavía oportuna su publicación: teníamos la esperanza de desarrollar el tema en un libro que debería aparecer algún tiempo después. Ello no fue posible. Los afanes de la vida de un joven abogado, recién casado y con hijos, se confabularon en aquel momento para que el programa no se cumpliera. Tuvimos que 
cho como libertad ${ }^{62}$. En esta obra se llegó a la tesis que se conocería años más tarde, gracias a Miguel Reale, con la denominación de «teoría tridimensional del derecho" ${ }^{63}$.

Presentada la tesis del año 1950 continuamos nuestra búsqueda de respuestas. Clarificado nuestro pensamiento sobre el derecho, nos sentíamos en la necesidad de abordar el tema referido a la determinación de la naturaleza o estructura de aquel ente que era su creador, protagonista $y$ destinatario. Es decir, de la persona ${ }^{64}$.

esperar algunos años para que apareciera su complemento La noción juridica de persona en 1962 y en Derecho y persona en 1992. No obstante, a partir de 1984, año en el que retornamos de Europa, empezamos a publicar diversos ensayos en los que se volvía sobre el tema profundizando algunos aspectos del trabajo de 1950 y desarrollando otros. Hay otra razón adicional. Si bien la tesis, como anota Carlos Cossio, causó revuelo por su novedad en el claustro universitario, nadie se pronunció sobre ella hasta después de un buen tiempo. Recordamos que la tesis, aún inédita, es comentada por Mario Alzamora Valdez en su libro de 1968 titulado La Filosofía del Derecho en el Perí (editada por Minerva). Ella es referida en el capítulo denominado «El pensamiento actual» (pp. 119 a 124) y en el sub capítulo "Las nuevas doctrinas en el Perú», donde cita las obras de José León Barandiarán. Al comentar la tesis considera que el "mayor mérito" del autor es el haber bosquejado desde su ángulo, en 1950, la teoría tridimensional del derecho (p. 123).

62 La tesis permaneció inédita durante 37 años, desde 1950 hasta 1987, año de la primera edición. No obstante, como anota Domingo García Belaunde en la Nota Preliminar, "la tesis tuvo una suerte singular: de ella se hicieron diversas copias que circularon sigilosamente por diversas manos, tanto en el país como en el extranjero, a veces con consentimiento del autor, y otras veces sin él. Esto explica como el maestro argentino Carlos Cossio, al reseñar dicho libro en "La Ley" (García Belaunde se refiere al libro del autor de 1962 La noción juridica de persona) hiciera de aquella una acertada como generosa apreciación". García Belaunde luego de señalar que el ensayo "ha permanecido alejado del gran público, y en especial de las más recientes hornadas universitarias" se pregunta "¿a qué se debe que su autor, no obstante haber obtenido tan auspicioso recibimiento en el claustro y en el mundo académico, no se haya animado a darla a la imprenta?». La respuesta a la pregunta que se formula García Belaunde está dada en la nota anterior.

63 Cabe señalar que la investigación de Reale y la nuestra, que llegaron a la misma conclusión más allá de los matices que la diferencian, se llevaron a cabo por la misma época sin que ninguno de los autores conociera el desarrollo de los trabajos del otro. En la Nota Preliminar al libro El derecho como libertad, escrita por Domingo García Belaunde analiza este aspecto con conocimiento de causa.

64 Al referirse al concepto "persona" se le suele acompañar generalmente con la expresión "humana". Nosotros no nos sentimos en la necesidad de hacerlo desde que, desde una perspectiva filosófica y desde nuestro punto de vista, persona es sólo el ser humano, individual o colectivamente considerado. 
La reflexión sobre el ente "persona", con la intención de aproximarnos lo más posible al conocimiento de su estructura, culminó con la elaboración de un segundo libro que recogía nuestras indagaciones y conclusiones sobre la materia. La obra fue editada en $1962^{65}$ por la Universidad Nacional Mayor de San Marcos con el título de La noción juridica de person $a^{6 \sigma}$. La incertidumbre que reinaba en aquel entonces sobre la calidad ontológica de la persona -en cuanto ser humano- motivó el que iniciáramos esta investigación.

En dicho libro ${ }^{67}$ decíamos «que el de la persona es un tema problemático porque, después de siglos, seguimos sintiendo la urgencia, la ineludible necesidad de saber qué es ella para el Derecho. Y nos vemos forzados a decidir dentro de un muestrario asombrosamente frondoso de definiciones que se han venido acumulando, como tierras de aluvión, en el decurso de los años". Agregábamos que «no podemos eludir la insosegable tarea de revisar estas posiciones, de repensarlas, de compaginarlas si ello fuere posible" ${ }^{68}$. Lo expuesto justifica y explica el por qué abordáramos en aquel entonces el intrincado asunto de saber en que consistía, ontológica y jurídicamente, el ente que somos.

Desde la publicación de dicha obra hasta la fecha hemos desarrollado algunos aspectos de su contenido a través de diversos ensayos, publicados fundamentalmente a partir de 1984.

Las conclusiones a que llegáramos en las indagaciones antes reseñadas encontraron su expresión normativa en el Libro Primero, sobre el Derecho de las Personas, del Código civil peruano de 1984.

65 De este libro se editó una segunda edición en el año de 1968, la misma que también lleva el sello editorial de la Universidad Nacional Mayor de San Marcos de Lima.

66 La primera cdición data de 1962 y la segunda, como está dicho, fue publicada por la misma Universidad en 1968. La editorial Depalma nos contrató en 1980 una tercera edición. Cuando empczamos a revisar el texto comprendimos que habíamos superado algunos aspectos de la obra. En ese entonces teníamos clara la diferencia - no percibida aún nítidamente en la década de los años sesenta - entre los concepros sujeto de derecho y persona. Ello motivó que le solicitáramos a don Roque Depalma la rescisión del contrato, a lo que accedió generosamente.

67 Los críticos de la obra, entre ellos Carlos Cossio, señalaron que se trataba del primer libro que se escribía en lengua castellana sobre el tema dedicado íntegramente a desentrañar la noción de persona.

68 Carlos Fernández Sessarego, La noción juridica de persona, op. cit., p.17. 
En 1992, se editó por la Universidad de Lima un tercer libro titulado Derecho y persona en el cual, al ampliarse algunos aspectos relacionados con la teoría tridimensional del derecho y precisarse sus antecedentes así como sus diferencias con la concepción de Miguel Reale, se desarrollan también algunos aspectos vinculados con nuestra concepción sobre la persona. En esta obra, que completa la trilogía de trabajos sobre los temas antes referidos, se intentó precisar mejor la relación existente entre el derecho y la persona.

\section{La pregunta sobre el derecho}

Como lo anotáramos, en nuestro trabajo de 1950, publicado en 1987, después de efectuar una crítica de las concepciones históricas sobre lo que se entendía con el concepto «derecho», llegábamos a la conclusión de que éste consistía en la interacción dinámica de tres dimensiones como son la vida humana social, los valores y las normas jurídicas. De esta interacción surgía un concepto unitario de lo que es «derecho".

Considerábamos en aquel trabajo de mitad del siglo pasado que el derecho no podía reducirse a ninguno de los tres objetos que lo integraban. Es decir, que no era sólo vida humana social, ni sólo valores o normas jurídicas. Estas visiones del derecho eran fragmentarias, incompletas, que no daban cuenta cabal, totalizadora, de lo que se comprende bajo el concepto "derecho".

En nuestro trabajo de 1950 manifestábamos que «la realidad jurídica es compleja" desde que "existe una pluralidad de elementos que integran la ciencia jurídica. Y para captar adecuadamente "lo jurídico" se requiere no prescindir de ninguno de ellos. Los estratos ontológicos, estimativo y lógico se exigen mutuamente en una unidad. En la unidad del derecho. Podemos apreciar aisladamente la conducta como libertad, las normas como pensamiento y los valores como seres ideales objetivos con validez propia, pero para captar "lo jurídico" en su integridad debemos considerar aquelias categorías en su inescindible unidad".

En aquel texto expresábamos que «no hay derecho sin conducta humana en su interferencia intersubjetiva, sin valores inmanentes a ella sin dejar por esto de ser objetivos, sin normas que representen a la conducta estimativa y que comportan una coacción. Podemos desplegar aquellos elementos y hacerlos tema, respectivamente, de la Ontología, la Estima- 
tiva y la Lógica Jurídica; más, si queremos apreciar el derecho, "lo jurídico", tenemos que considerarlos en su inescindible unidad, en su mutua exigencia» ${ }^{69}$.

Páginas más adelante decíamos que es así que «se despliegan los elementos que conforman el Derecho; elementos que se exigen mutuamente sin confundirse y que cobran unidad en el «objeto" Derecho. Conducta, norma y valor son los elementos ontológico, lógico y estimativo del Derecho que en una unidad integral motivan su aparición. Y el Derecho no es ninguno de estos elementos en forma aislada. El Derecho no es conducta, el Derecho no es valor, el Derecho no es norma. El Derecho es la integración de aquellos elementos; es conducta humana en su interferencia intersubjetiva, realizando dejando de realizar valores, representada a través de normas que son juicios imputativos de deber ser de carácter disyuntivo" ${ }^{70}$.

Años más tarde, en 1992, retomábamos esta posición al manifestar que «el Derecho resulta así una complejidad desde que su estructura se integra, en dinámica interacción unitaria ${ }^{71}$, en un proceso sin tregua, por conductas humanas intersubjetivas, normas y valores. El Derecho no se agota, no se consume, en ninguna de aquellas dimensiones. Es imprescindible su simultánea presencia, que deriva de una recíproca exigencia, para que se constituya, en su totalidad, la experiencia jurídica, para que podamos referirnos a "lo jurídico". Ninguna de aquellas dimensiones per se es Derecho, pero tampoco ninguna puede soslayarse si se pretende aprehender el Derecho como una totalidad" ${ }^{72}$.

Debemos anotar, sin embargo, que de dichas tres dimensiones, si bien ellas se presentan simultáneamente en interacción dinámica, la pri-

69 Carlos Fernández Sessarego, El derecho como libertad, segunda edición, p. 121.

70 Carlos Fernández Sessarego, El derecho como libertad, op. cit, p. 125.

71 En nuestras lecciones universitarias ante la perplejidad de muchos estudiantes sobre la significación de la expresión "interacción dinámica» solemos utilizar un ejemplo de la vida que nos ha sido útil para que los alumnos comprendan sus alcances. Así, a semejanza del concepto "Derecho", aludimos al concepto "motor" donde para que podamos designarlo como tal debe encontrarse en interacción dinámica de todas las piezas o partes que lo integran, las mismas que, por lo demás, son heterogéneas. Si faltara alguna de dichas piezas ya no nos encontraríamos frente a un "motor" sino a una simple estática yuxtaposición de tales piezas. En esta situación, como es obvio, no interesa el que prescindamos de alguna de cllas.

72 Carlos Fernández Sessarego, Derecho y persona, Editorial Grigley, tercera edición, p. 47. 
mordial es la vida humana social, pues sin ella carecería de sentido tanto su valoración como su regulación normativa. Sin vida humana social no es imaginable el derecho ${ }^{73}$.

Es por ello que si revisamos la historia de la jusfilosofía ésta nos muestra que los autores, a través de los siglos, han propuesto el que «alguna de tales específicas dimensiones de lo jurídico se constituya en el objeto de estudio de la ciencia jurídica». Es por ello que, como remarcáramos en dicha obra de 1992, "las visiones fragmentarias que ofrecen las distintas escuelas o corrientes de pensamiento sobre el Derecho, por más elaboradas y coherentes que sean, no captan el fenómeno jurídico tal como discurre en la realidad de la vida». Esas escuelas, llámense jusnaturalismo, positivo-formalista o sociologismo o realismo, "sólo llegan a mostrar aspectos parciales de dicha realidad. Ello, de hecho, impide al científico del Derecho obtener una respuesta unitaria y global sobre la experiencia jurídican ${ }^{74}$.

En el mencionado libro, Derecho y persona, analizamos extensamente cada una de las posiciones unidimensionales antes referidas, poniendo énfasis en sus aportes y mostrando su insuficiencia para una concepción integral del derecho, es decir, tal como se presenta en la experiencia.

\section{La interrogación sobre la "persona»}

Despejada la incógnita sobre lo que es el derecho debemos referirnos necesariamente a su creador, protagonista y destinatario, dentro del contexto referido en los parágrafos precedentes del presente trabajo. Es decir, encontrar la significación del concepto persona para el derecho.

Como está dicho, del referido tema nos ocupamos por vez primera, en forma integral, en el libro antes citado titulado La noción jurídica de persona en 1962. Posteriormente, como también lo hemos referido, hemos vuelto sobre el asunto en numerosos ensayos dispersos en libros y revistas a partir de 1984 .

73 En nuestro afán didáctico solemos ofrecer a nuestros alumnos un ejemplo al respecto. Así, les proponemos que si Caín no mata a Abel no hay Derecho. Es decir, el Derecho requiere primariamente de la presencia de conductas intersubjetivas, pues de no ser así la valoración o la regulación normativa carecerían de sentido.

74 Carlos Fernández Sessarego, Derecho y persona, op. cit., pp. 51-52. 
Como refiriéramos en La noción jurídica de persona ${ }^{75}$, Recaséns Siches tuvo el acierto metodológico de haber formulado con precisión las cuatro preguntas que deben o pueden formularse al tratar sobre la persona. $\mathrm{Si}$ bien discrepamos de algunas de las respuestas del tratadista en mención, consideramos oportuno señalar cuáles son tales preguntas ${ }^{76}$, para luego proponer nuestras respuestas.

En primer lugar, el autor hispano, avecindado en América, se pregunta sobre "qué quiere decir en términos jurídicos, qué significa tener dentro de un ordenamiento jurídico la calidad de persona; qué es ser persona en Derecho" ${ }^{77}$. Según el autor, corresponde a la Teoría General determinar el concepto jurídico de persona con alcance general.

En segundo término Recaséns Siches se pregunta sobre «quiénes son los entes sobre los cuales recaiga esa calificación jurídica de persona; por ejemplo, refiriéndose a las personas individuales en Derecho, preguntarse quiénes son los hombres a los que el Derecho concede personalidad y refiriéndose a las llamadas personas colectivas, preguntarse cuáles son las asociaciones a las que el Derecho otorga personalidad». Según el autor, la respuesta a esta pregunta es tema propio de la Dogmática del Derecho positivo.

La tercera interrogante se contrae a saber "en qué consiste el ser de esos entes a los que el Derecho otorga personalidad, cuáles sean sus dimensiones reales; verbigracia, refiriéndonos a las personas individuales, indagar en qué consista la esencia de lo humano, sus modalidades y sus manifestaciones; y por lo que atañe a las personas colectivas, esclarecer en qué consista la realidad de una asociación, de una corporación, de una fundación". El tema relativo al conocimiento de la naturaleza de dichos entes, según Recaséns, «es ajeno en sentido estricto a la consideración jurídica». El asunto se inscribe en el estudio del hombre, del ser humano.

En cuarto lugar, Recaséns Siches considera necesario uplantear desde un punto de vista estimativo, de valoración, de política legislativa, la cuestión de a quién el Derecho debería conceder la personalidad; esto es lo que se hace, por ejemplo, cuando criticamos la institución de la esclavitud, afirmando que a todos los hombres debe corresponder la persona-

75 Carlos Fernández Sessarego, La noción juridica de persona, op. cit, p. 27.

76 Luis Recaséns Siches, Tratado de Filosofia del Derecho, 2a cdición, pág. 260.

77 Luis Recaséns Siches, Ibid, p., 260. 
lidad jurídica, o cuando se pide que el Estado no admita otras personas colectivas que aquéllas que él instituya, o cuando se postula lo contrario, esto es, que la conceda a cuantos entes colectivos surjan espontáneamente».

\subsection{Qué es persona para el derecho}

Creemos necesario, tras la guía metodológica trazada por Recaséns Siches, intentar responder, desde nuestra personal perspectiva, las preguntas certeramente por él planteadas.

A la primera pregunta sobre qué es ser persona dentro de un ordenamiento jurídico debe responderse, desde nuestro punto de vista, expresando que "persona" es el sujeto de derecho. Sujeto de derecho, bien lo sabemos, es el ente al cual el ordenamiento jurídico positivo de cada país le atribuye «situaciones jurídicas subjetivas", vale decir, un plexo de derechos subjetivos y de deberes.

Sujeto de derecho es así, una categoría jurídica formal, un puro concepto, un centro de referencias normativas. Saber sobre cuál sea su contenido es materia de otras interrogantes y de sus respectivas respuestas. A ellas nos referiremos de inmediato.

\subsection{Quiénes son personas}

A la segunda interrogante, sobre quiénes sean los entes sobre los cuales recaiga la calificación de "persona", debemos responder, siempre desde nuestra perspectiva, que los seres humanos son los únicos entes que, desde la realidad de la vida, merecen dicha calificación. Está demás decir que se trata de todos los seres humanos, sin excepción, y sólo los seres humanos con exclusión de cualquier otro ente de la naturaleza. El ser humano, por libre y coexistencial, es el creador, protagonista y destinatario del derecho. Lo hemos ya expresado en precedencia aunque vale la pena reiterarlo: el derecho es una exigencia existencial del ser humano, en cuanto libre y coexistencial. No cabe convivencia sin reglas de conducta.

$\mathrm{Al}$ respecto, no debe perderse de vista que son sujetos de derecho los seres humanos individual o colectivamente considerados. Tradicionalmente no habían más sujetos de derecho que las llamadas persona "natural» y persona «jurídica». En la actualidad, y siempre desde nuestro 
punto de vista, la codificación debe otorgar la calidad de sujeto de derecho, además de los indicados, a otros dos sujetos de derecho como son el concebido o persona por nacer y la organización de personas «no inscrita" o de "hecho", como se le viene calificando en algunas legislaciones y por la doctrina. Es decir, existen cuatro sujetos de derecho, dos sujetos de derecho individuales, el concebido y la persona natural, y dos sujetos de derecho colectivos, la organización de personas no inscrita o de hecho y la organización de personas inscrita o persona jurídica. En cualquiera de ellas el ser humano es el protagonista.

El apreciar la existencia de dos nuevos sujetos de derecho se nos presentó cuando tuvimos el encargo de redactar el proyecto de Libro Primero del actual Código civil peruano de 1984 dedicado al Derecho de las Personas. Fue en ese momento en que comprendimos que, además de los dos sujetos de derecho tradicionales, es decir, la persona natural y la persona jurídica, existían otros dos sujetos de derecho no reconocidos por los ordenamientos jurídicos positivos.

Conocemos sólo dos excepciones al respecto. La primera es la del Código civil argentino de 1869 que le concede ciertos derechos al concebido - designado por Vélez Sarsfield como «persona por nacer» - aunque sin otorgarle, directamente y a plenitud, la calidad de sujeto de derecho, lo que es explicable si nos atenemos a la época en que se produce tal reconocimiento siguiendo, con acierto, la huella de Teixeira de Freitas. No obstante, el mencionado Código, como es también comprensible por su longevidad, no reconoce la calidad de sujeto de derecho que corresponde a la organización de personas «no inscrita» no obstante que, a imagen y semejanza de la persona jurídica, actúa en la realidad y realiza actos jurídicos.

Cabe remarcar que la organización de personas «no inscrita» realiza, como está dicho, actos jurídicos dentro del derecho común. Ella, sin embargo y por ello, no se beneficia con el régimen de excepción o de privilegio derivado del hecho formal de la inscripción de una organización de personas en un registro público, mediante el cual se finge la creación de un centro unitario ideal al cual se imputan derechos y deberes. Ello supone, por consiguiente, que ninguno de los miembros de la persona jurídica es responsable de las obligaciones que ella contrae, lo que no ocurre en el caso de la organización de personas no inscrita donde existe un natural condominio sobre los bienes que constituyen su patrimonio y son codeudores de las obligaciones contraídas. 
La segunda excepción de la que estamos informados es la del Código civil italiano de 1942 que reconoce la calidad de sujeto de derecho a las asociaciones y a los comités "de hecho», aunque desconoce la calidad de sujeto de derecho que puede tener la fundación intervivos, entre el momento en que el o los fundadores ordenan el inicio de su actividad y el instante en que se produce su inscripción o su reconocimiento gubernativo, según el $\mathrm{caso}^{78}$. El mencionado Código no reconoce la calidad de sujeto de derecho que le corresponde al concebido en su calidad de ser humano desde el instante de la concepción, es decir, de aquel instante en que se produce la fecundación del óvulo por un espermatozoide, mediante la fusión de sus núcleos, acto que se conoce como «singamia», y se concluye en un lapso aproximado de 24 horas al decir de los científicos.

El Código civil peruano de 1984 admite una nueva sistematización del sujeto de derecho. Considera la existencia de cuatro de ellos, dos individuales, concebido y persona natural, y dos colectivos, organización de personas «no inscrita» y organización de personas inscrita o persona jurídica. El sujeto de derecho, en cualquiera de dichas situaciones es, siempre y únicamente, el ser humano, individual o colectivamente considerado. Se trata de cuatro "maneras de ser", de cuatro momentos o instantes en el devenir de la vida humana.

El segundo párrafo del artículo $1^{\circ}$ del Código civil peruano reconoce la calidad de sujeto de derecho que corresponde al concebido en cuanto ser humano. En los artículos $124^{\circ}$ a $126^{\circ}$ se hace referencia a la asociación no inscrita; en los artículos $127^{\circ}$ a $129^{\circ}$ se regula la fundación no inscrita y en los artículos $130^{\circ}$ a $133^{\circ}$ se norma el comité no inscrito. La doctrina nacional no designa más a estas organizaciones de personas no inscritas como "de hecho" o «irregulares», como sucedía en precedencia, pues ellas están, desde 1984, reconocidas y reguladas por la ley. Dejaron, así, de ser «de hecho» o «irregulares», para ser «de derecho " $y$ «regulares».

No obstante lo dicho en el párrafo anterior, la Ley General de Sociedades de 1997 designa a las organizaciones de personas «no inscritas" -

78 En Italia, como es sabido, el inicio de las actividades de las personas jurídicas se produce a raíz de su reconocimiento gubernativo, a diferencia de otras legislaciones donde ello ocurre a partir de su inscripción en un registro público. En Italia se ha cricicado tal solución, pues ella atenta contra la libertad de asociación al dar injerencia al gobierno en un acto que depende sólo de la libertad de las personas. 
en este caso a las sociedades - como «irregulares», a pesar que la propia ley las "regula" al reconocerlas como sujeto de derecho, es decir, al atribuirles derechos y deberes ${ }^{79}$. En efecto, el artículo $423^{\circ}$ de la citada ley prescribe que: «Es irregular la sociedad que no se ha constituido e inscrito conforme a esta ley o la situación de hecho que resulta de que dos o más personas actúan de manera manifiesta en sociedad sin haberla constituido e inscrito. En cualquier caso una sociedad adquiere la condición de irregular».

Contrariamente a la tesis generalmente aceptada, nosotros no pretendemos limitar o restringir lo que es la naturaleza de la "persona jurídica» a tan sólo su elemento puramente formal, como es la creación de un centro unitario de imputación de derechos y deberes de naturaleza ideal. Si bien esta es la nota que la tipifica y determina, pues a raíz de la inscripción formal se le otorga un régimen de excepción, no podemos por ello dejar de lado, cuando nos referimos a su naturaleza, que ella está integrada por personas, las mismas que crearon libremente dicho centro ideal. Por lo demás, para su creación las personas que la integran convinieron en los valores que deberían perseguir y, sobre todo, que ellas son las que actúan en la realidad realizando actos jurídicos dentro de una dimensión axiológica ${ }^{80}$. En la naturaleza de la persona jurídica, por consiguiente, no sólo encontramos su dimensión o estructura formal, sino a las personas que la componen y los valores perseguidos a través de una actividad en común. El derecho, bien lo sabemos, no se

79 La Sección Quinta de la "Ley General de Sociedades", publicada en el diario oficial "El Peruano" con fecha 9 de diciembre de 1997, está dedicada a las «sociedades irregulares", cuando ellas adquirieron la calidad de "regulares" desde el reconocimiento de la organización de personas no inscrita como sujeto de derecho por el Código civil peruano de 1984. El peso de la tradición apabulla, a menudo, a los juristas.

80 Ver Carlos Fernández Sessarego, "Naturaleza tridimensional de la persona jurídica", en la revista Derecho PUC, editada por la Pontificia Universidad Católica del Perú, N 52, Lima, abril-diciembre de 1999; Visión tridimensional de la persona jurídica en "Anales" de la Academia Nacional de Derecho y Ciencias Sociales de Buenos Aires, Buenos Aires, 1995: en Revista del Colegio de Abogados de Buenos Aires, vol. 56, $\mathrm{N}^{\circ} 3$, Buenos Aires, julio-setiembre de 1995 y en Revista Jurídica del Perú, $\mathrm{N}^{\circ}$ 4, Trujillo, octubre-diciembre de 1995 y en Iuris dictio, Año II, N³, Lima, 1997. Además, ver "¿La persona juridica, es distinta de sus miembros?" en Gaceta Jurídica, Tomo 50, Lima, enero de 1988 y La irrealidad del artículo $78^{\circ}$ del Código civil, en Gaceta Jurídica, Tomo 51, Lima, febrero de 1998. 
reduce a puras formas, a meros conceptos vacíos de contenido. El contenido de las normas, que son seres ideales, son las conductas humanas intersubjetivas valiosamente consideradas.

\subsection{En qué consiste el ser de la persona}

Todos los sujetos de derecho, ya sean personas por nacer, personas nacidas o naturales o personas organizadas, con o sin inscripción en un registro público, son seres humanos, sin excepción. Es decir que sólo los seres humanos, en cualquiera de sus "cuatro maneras de ser", son sujetos de derecho, con exclusión de cualquier otro ser de la naturaleza.

Como ha quedado demostrado, los esclavos nunca dejaron de ser personas. Sólo se limitó, en diversa medida según las diversas épocas históricas, su capacidad de ejercicio. Nunca dejaron de ser seres ontológicamente libres y capaces y, por consiguiente, aptos para gozar de todos sus derechos naturales aunque la ley o la costumbre restringieran su capacidad de ejercicio.

En su lugar hemos referido que el ser humano es una unidad psicosomática sustentada en su libertad. La libertad constituye el núcleo existencial o centro espiritual del ser humano.

No compartimos la posición de Recaséns Siches en el sentido de que "lo que en el Derecho funciona como persona no es la totalidad del hombre, en su ser íntegro, en su plenaria realidad individual, sino una especial categoría jurídica que se adhiere a esa realidad, pero sin contenerla dentro de sí» ${ }^{81}$. Por el contrario, la persona, desde nuestro punto de vista, es un concepto jurídico cuyo contenido u objeto no es un ser humano parcial sino un ser humano plenario y viviente, integral. Un ser humano de carne y hueso, como gustaba decir a Unamuno. Es decir, lo que funciona como persona para el derecho es la "totalidad" del ser humano o del «hombre».

\subsection{A quiénes el derecho debería considerar personas}

Esta última cuestión se refiere a quiénes el derecho positivo debería otorgar la categoría de persona. La respuesta, según un sector ampliamente mayoritario de la doctrina, corresponde a la política legislativa. 
Desde nuestra perspectiva la pregunta dejó de tener vigencia en el momento en el cual la doctrina abandona una concepción puramente formalista-positivista del derecho para asumir una visión humanistapersonalista, donde el ser humano es el centro y el eje del derecho. Si esto es así, cualquier respuesta que pueda suministrar la política legislativa, si quiere ser fiel a la realidad, no tiene otra opción o alternativa válida que declarar que sólo el ser humano es persona, es sujeto de derecho. Una posición diferente distorsionaría el sentido del derecho.

El derecho positivo no tiene otra opción, reiteramos, que reconocer que no hay más personas que los seres humanos, individual o colectivamente considerados. Es decir, las cuatro "maneras del ser» a las que hemos hecho referencia con anterioridad. No cabe la posibilidad que la política legislativa concluya resucitando a Incitatus - el caballo al cual Calígula hizo Cónsul - como persona o que nos recomiende que se otorgue la calidad jurídica de persona al «césped», que supuestamente tiene el derecho a no ser hollado por el ser humano, o al "camarón" que tendría el derecho a no ser pescado porque tendría derecho a la vida.

En estas hipótesis referidas en el párrafo precedente, son los seres humanos los que tienen el derecho a contar con áreas verdes bien conservadas para su esparcimiento y por razones estéticas. Y es también a los seres humanos a los que le interesa que, para su deleite como consumidor, no se extinga el camarón a consecuencia de una pesca incontrolada.

En síntesis, persona es el sujeto de derecho. Sujeto de derecho que no es otro que el ser humano, individual o colectivamente considerado. Ser humano cuya naturaleza es ser una unidad psicosomática sustentada en su libertad. Ninguna política legislativa debería contrariar esta realidad ya que ello tendría como consecuencia el desnaturalizar el sentido del derecho para la vida humana. Es decir, del derecho creado, como exigencia existencial, por seres humanos libres y coexistenciales, que requieren de normas jurídicas, valiosamente concebidas, que le permitan realizar su personal proyecto de vida dentro del bien común. 